\title{
Regulation and Symbiotic Role of nirK and norC Expression in Rhizobium etli
}

\author{
Nicolás Gómez-Hernández, ${ }^{1}$ Alma Reyes-González, ${ }^{1}$ Cristina Sánchez, ${ }^{2}$ Yolanda Mora, ${ }^{1}$ María J. Delgado, ${ }^{2}$ \\ and Lourdes Girard' \\ ${ }^{1}$ Programa de Genómica Funcional de Procariotes, Centro de Ciencias Genómicas, Universidad Nacional Autónoma de \\ México, Ap. Postal 565-A, Cuernavaca, Morelos, 62271, México; ${ }^{2}$ Departamento de Microbiología del Suelo y Sistemas \\ Simbióticos. Estación Experimental del Zaidín, CSIC. Ap. Postal 419, 18080 Granada, Spain
}

Submitted 29 July 2010. Accepted 20 October 2010.

\begin{abstract}
Rhizobium etli CFN42 is unable to use nitrate for respiration and lacks nitrate reductase activity as well as the nap or nar genes encoding respiratory nitrate reductase. However, genes encoding proteins closely related to denitrification enzymes, the norCBQD gene cluster and a novel nirKnirVnnrRnnrU operon are located on pCFN42f. In this study, we carried out a genetic and functional characterization of the reductases encoded by the $R$. etli nirK and $n o r C B$ genes. By gene fusion expression analysis in free-living conditions, we determined that $R$. etli regulates its response to nitric oxide through NnrR via the microaerobic expression mediated by FixKf. Interestingly, expression of the $n o r C$ and nirK genes displays a different level of dependence for NnrR. A null mutation in $n n r R$ causes a drastic drop in the expression of norC, while nirK still exhibits significant expression. A thorough analysis of the nirK regulatory region revealed that this gene is under both positive and negative regulation. Functional analysis carried out in this work demonstrated that reduction of nitrite and nitric oxide in $R$. etli requires the reductase activities encoded by the norCBQD and nirK genes. Levels of nitrosylleghemoglobin complexes in bean plants exposed to nitrate are increased in a nor $C$ mutant but decreased in a nirK mutant. The nitrate-induced decline in nitrogenase-specific activity observed in both the wild type and the nor $C$ mutant was not detected in the nirK mutant. This data indicate that bacterial nitrite reductase is an important contributor to the formation of NO in bean nodules in response to nitrate.
\end{abstract}

The nitrogen cycle includes a series of both reductive and oxidative reactions in which prokaryotes have an important role. Dinitrogen $\left(\mathrm{N}_{2}\right)$ is incorporated into the biosphere by biological or chemical fixation to generate ammonium and returns to the atmosphere by denitrification. The biological denitrification process consists of a sequential reduction of nitrate or nitrite to nitrogen gas when oxygen concentrations are limited. Reduction of nitrogen oxides is coupled with energy conservation and permits cell growth under anaerobic conditions. The denitrification process depends on four nitrogen oxide reductases: respiratory or periplasmic nitrate reductase, nitrite reductase, nitric oxide reductase, and nitrous oxide reductase, encoded by narGHJI (or napEDABC), nirK (or nirS), norCBQD, and nosRZDYFLX genes, respectively (van Spanning et al. 2005, 2007; Zumft and Körner 1997).

Corresponding author: L. Girard; Telephone: +(52) 777 3291896; Fax: +(52) 777 3175581; E-mail: girard@ccg.unam.mx
In general, expression of denitrification genes requires a low oxygen concentration, the presence of a nitrogen oxide, and control by transcriptional regulators belonging to the CRP/FNR family (Baek and Shapleigh 2005; Bedmar et al. 2005; Hendriks et al. 2000; Mesa et al. 2003; Tosques et al. 1997; Wang et al. 1999; Zumft and Körner 1997; Zumft 2002). FNR is a protein that contains an $\mathrm{O}_{2}$-sensitive $[4 \mathrm{Fe}-4 \mathrm{~S}]^{2+}$ cluster that directly senses oxygen. In Escherichia coli, it functions as a global regulator controlling the expression of up to 100 genes in response to oxygen limitation, and its active DNAbinding form is a homodimer containing two $\left[4 \mathrm{Fe}-4 \mathrm{~S}^{2+}\right.$ clusters (Kang et al. 2005; Kiley and Beinert 2003). The protein binds through a helix-turn-helix motif to the promoter region of target genes, repressing the expression of genes for aerobic respiration and inducing genes involved in alternative forms of anaerobic respiration.

The consensus DNA binding site for $E$. coli FNR is a symmetrical motif (TTGAT-N4-ATCAA) called the FNR box or anaerobox (Kiley and Beinert 1999, 2003; Körner et al. 2003). FNR homologs have been identified in a wide number of bacteria. Some of these proteins conserve an N-terminal cysteinerich motif, which binds the $\mathrm{Fe}-\mathrm{S}$ cluster, while others, like the members of the FixK group, lack it. Based on genome analysis, the number of members of the CRP/FNR family now includes 369 members distributed in 14 phylogenetic branches (Körner et al. 2003). The FnrN group of regulators includes putative proteins with a slight modification of the conserved cysteine motif of FNR, allowing the assembly of a $[4 \mathrm{Fe}-4 \mathrm{~S}]^{2+}$ cluster and thus redox sensing. On the other hand, regulators belonging to the FixK branch are structurally homologous to FnrN but lack the N-terminal cysteine-rich motif. A characteristic frequently found in sequenced bacterial genomes is the existence of multiple members of the CRP/FNR regulators in the same host (Körner et al. 2003).

The reduction of nitrite $\left(\mathrm{NO}_{2}^{-}\right)$to nitric oxide $(\mathrm{NO})$, the central reaction in denitrification, is catalyzed by nitrite reductase. There are two types of nitrite reductases with different prosthetic groups. The $\mathrm{Cu}$-containing nitrite reductase $(\mathrm{CuNir}$, encoded by nirK) uses copper as a redox active metal, and is a trimeric protein containing two types of copper centers. The other, a dimeric $c d_{l}$-type nitrite reductase (cytochrome $c d_{l}$ ), utilizes heme-bound iron and is encoded by the nirS gene. Phylogenetic distribution of NirK and NirS reductases appears to be random; however, even when both types of enzymes can be found in a single genus, they cannot coexist in a single bacteria (Shapleigh 2006; Zumft and Körner 1997).

Due to its toxicity, $\mathrm{NO}$ has to be reduced to nitrous oxide immediately. A membrane protein complex formed by two sub- 
units encoded by the nor $C$ and nor $B$ genes catalyzes the reduction of two molecules of $\mathrm{NO}$ to nitrous oxide $\left(\mathrm{N}_{2} \mathrm{O}\right)$ and water (cNOR). NorC is a $c$-type cytochrome, while NorB contains two $b$-type hemes. In general, nor $C B$ genes are clustered with the nor $Q$ and nor $D$ genes. Therefore, to remove the NO, reactions for reduction of nitrite and nitric oxide must be regulated in a concerted way (Hendriks et al. 2000; Philippot 2002; Zumft 2005). In addition to cNOR, another two different bacterial NOR have been characterized (qNOR and $\mathrm{qCu}_{\mathrm{A}} \mathrm{NOR}$ ) (de Vries et al. 2007; Zumft 2005).

In plants, NO has been proposed as a signaling molecule involved in diverse physiological processes, such as defense response, growth, and development (Besson-Bard et al. 2008). Nitric oxide in plants can be produced from nitrite via nonenzymatic or enzymatic pathways. Several enzymatic pathways have been proposed for the generation of NO in plants. One is a nitrate-dependent pathway that is catalyzed mainly by nitrate reductase. Additionally, two other enzymatic pathways that use L-Arg or polyamines as substrates have been reported. The corresponding enzymes in the last two pathways remain as yet unidentified, and the hypothesis that plants do possess a nitric oxide synthase (NOS)-like enzyme is highly controversial (Besson-Bard et al. 2008). The sources of NO in nodules are not clear; nodular NO may be a product of bacterial denitrifying metabolism (Meakin et al. 2007; Sánchez et al. 2010) or may also be produced in plant root tissue from arginine via an unidentified NOS-like enzyme (Baudouin et al. 2006). In symbiosis, NO is produced in early stages of the process and in the mature nodule. For example, in Lotus japonicus, a rapid and transient NO production is observed when roots are inoculated with Mesorhizobium loti (Shimoda et al. 2005). In Medicago spp., NO is involved in nodule formation and functioning (Ferrarini et al. 2008; Pii et al. 2007). In addition, modulation of NO levels are involved in the establishment of the symbiosis (Nagata et al. 2008). NO also interfere with nitrogen fixation in soybean (Trinchant and Rigaud1982), Alnus firma (Sasakura et al. 2006), and Lotus japonicus nodules (Kato et al. 2010; Shimoda et al. 2009). NO affect nitrogenase activity or can bind to leghemoglobin to form nitrosylleghemoglobin (Lb-NO) complexes in soybean nodules (Mathieu et al. 1998; Meakin et al. 2007; Sánchez et al. 2010).

Denitrification capability is widespread in prokaryotes, including nitrogen-fixing bacteria. Among rhizobia, only Bradyrhizobium japonicum, the microsymbiont of soybean, has been shown to reduce $\mathrm{NO}_{3}{ }^{-}$simultaneously to $\mathrm{NH}^{+}$and $\mathrm{N}_{2}$ when cultured microaerobically with nitrate as terminal electron acceptor and sole source of nitrogen. Denitrification in $B$. japonicum depends on the consecutive action of the napEDABC, nirK, norCBQD, and the nosRZDYFLX genes (Bedmar et al. 2005). Other rhizobia, like Sinorhizobium meliloti, are only partial denitrifyers that produce $\mathrm{N}_{2} \mathrm{O}$ as an end product, even when they contain the complete set of genes for microaerobic nitrate reduction (Becker et al. 2004; Holloway et al. 1996). The extreme situation is represented by Rhizobium sullae (formerly Rhizobium hedysari), which contains only the $\mathrm{Cu}$-containing nitrite reductase (Toffanin et al. 1996).

Rhizobium etli CFN42 fixes nitrogen in association with bean plants, and its genome contains a chromosome and six large plasmids (pCFN42a to pCFN42f) whose sizes range from 184.4 to $642.5 \mathrm{~kb}$ (González et al. 2006). In $R$. etli CFN42, some important regulatory elements present on the pSym in other Rhizobium species are not encoded on this replicon. A fix region containing copies of the fixK, fixNOQP, fixGHIS-stoR genes and the fixL gene, which controls the expression of fixKf, is located on pCFN42f (Girard et al. 2000; Granados-Baeza et al. 2007). Downstream of the pCFN42f fix region, there is a gene cluster related with the denitrification process that includes genes encoding for the $\mathrm{Cu}$-containing nitrite reductase (nirK), a cytochrome- $c$ type nitric oxide reductase (norCBQD), and a pseudoazurin ( $a z u P f)$ (Girard et al. 2000; González et al. 2006). An additional gene, $n n r R$, is also present in the nirK-norC region in $R$. etli. In $B$. japonicum NnrR was described as a transcriptional regulator for nirK and nor $C$ genes in the presence of $\mathrm{N}$ oxides (Mesa et al. 2003).

Previously, we reported that $R$. etli shows nitrite reductase activity after incubation of the cells under anaerobic conditions. In this condition, a $R$. etli nirK mutant exhibits a poor nitrite reductase activity and nitrite uptake. In addition, $R$. etli is not able to use nitrate for respiration and does not present nitrate reductase activity. These results indicate that $R$. etli CFN42 is a nondenitrifying bacteria (Bueno et al. 2005). Therefore, the presence of NirK and NorC coding regions in an otherwise nondenitrifying bacterium can be explained by proposing that these enzymes have an $\mathrm{N}$ oxide-detoxifying role in $R$. etli, thus preventing accumulation of $\mathrm{NO}$ inside the cell. To gain insight into how $R$. etli responds to reactive nitrogen species, we carried out a genetic and functional characterization of the reductases encoded by $R$. etli nirK and norC genes. Also, we analyzed the participation of different regulatory proteins in the control of the expression of these genes. Nitrogenase-specific activity and the proportion of Lb-NO complexes formed in bean nodules demonstrate that nor $C$ has an important role in the microsymbiont in protection from $\mathrm{NO}$ and indicates that bacterial nitrite reductase is an important contributor to the formation of $\mathrm{NO}$ in nodules in response to nitrate.

\section{RESULTS}

Structural organization of $\boldsymbol{R}$. etli nirK and norC region.

In $R$. etli CFN42, genes encoding denitrification enzymes were identified on plasmid pCFN42f. Genes located in this region include those encoding proteins with significant similarity to $\mathrm{Cu}$-containing nitrite reductase (nirK), cytochrome- $c$ type nitric oxide reductase (nor $C B Q D$ ), and pseudoazurin $(a z u P f)$. Neither genes encoding for a respiratory nitrate reductase (nap or nar genes) nor for the respiratory nitrous oxide reductase (nos genes) were found in the $R$. etli genome. Similar to denitrifyers, the $R$. etli nor gene cluster consists of nor $C B Q D$. An additional gene, annotated as norE, that codifies for an accessory protein of the nitric oxide reductase in $S$. meliloti (SMa1279) was found upstream of the norC operon. The $R$. etli nirK gene is transcribed in the opposite direction of open reading frame (ORF) RHE_PF00524, which encoded for a hypothetical protein similar to $\mathrm{NnrS}$ from Rhizobium sp. strain NGR234 (NGR_c09940) (Fig. 1).

In general, the nirK gene is clustered with nirV, an ORF that encodes for a putative periplasmic nitrite reductase. In $R$. etli CFN42, the structural arrangement of the nirK-nirV region suggests that these genes are part of the same operon. The predicted translational start of the nirV coding region is located 82 bp downstream of the nirK stop codon. Two additional ORF are located in the proximity of nirK and nirV in R. etli, nnrR, which encodes NnrR, the FNR-type transcriptional regulator of denitrification genes, and RHE_PF00528, similar to denitrification regulator protein $\mathrm{NnrU}$. The translational start of $n n r R$ is located just 38 bp downstream of the nirV coding region, while the intergenic region between $n n r R$ and $n n r U$ coding regions comprises only 13 bp (González et al. 2006; Kazusa DNA Research Institute Rhizobase).

To determine if nirK, nirV, nnrR, and $n n r U$ are arranged as an operon, we evaluated microaerobic expression of these genes by reverse transcription-polymerase chain reaction (RTPCR). An insertional mutation within the nirK coding region 
abolished the expression of $n n r R$, indicating that a mutation in this gene exerts a polar effect on the expression of $n n r R$ (data not shown). In addition, the synthesis of different cDNA products corresponding to nirK-nirV, nirV-nnrR, or nirV-nnrU in the wild-type strain demonstrates that, in $R$. etli, nirK, nirV, $n n r R$, and $n n r U$ constitute an operon.

To predict the location of the promoter for the $R$. etli norC and nirK operons, the transcriptional start sites of each transcriptional unit were identified in assays using the rapid amplification of cDNA 5' ends (RACE). Total RNA was purified from wild-type cells cultured under microaerobic conditions. Our results show that the $R$. etli nor $C$ transcriptional start site is a $\mathrm{G}$ located 60 nucleotides upstream of the putative translational start codon. Analysis of the DNA region upstream of the norC gene revealed the presence of a purine-rich Shine-Dalgarno-like sequence (AAGGGA) six bases in front of the norC ATG codon. We also identified a sequence similar to the consensus for the FNR-DNA binding site (5'-TTGCG-N4AACAA-3') (Fig. 2A) centered at position -43.5 bp from the nor $C$ transcriptional start site.

For $R$. etli nirK, the transcriptional start site was defined as an A located $43 \mathrm{bp}$ upstream of the putative translation start. Similar to norC, a possible Shine-Dalgarno sequence (AGGA GA) was located six bases upstream from the putative translation start of nirK. Three sequences with high similarity to FNRbinding sites (TTGCG-N4-GTCAA, TTGTG-N4-CACAA, and TTGAG-N4-CGCAA) were identified in the nnrS-nirK intergenic region. They were named according to their relative distance from the nirK transcription start site as anaerobox 1,2, or 3 (ANB1, ANB2, or ANB3, respectively). The ANB1 located is at -42.5 , ANB2 at -65.5 and ANB3 at -96.5 bp (Fig. 2B). Interestingly, overlapping with the ANB2 there is a sequence similar to the NifA-binding site (5'-TGT-N10-ACA) (upstream activator sequence) without any putative -12/-24 type promoter in the region.

\section{Oxygen as a major signal}

for $R$. etli nirK and nor $C$ gene expression.

In B. japonicum, the expression of nir and nor genes in response to low oxygen concentration and NO (or a chemically related species) is under the control of FixK and NnrR, respectively, which are two regulatory proteins belonging to the CRP/FNR family (Mesa et al. 2003). Presence of putative class II promoters in the $R$. etli nor $C$ and nirK regulatory regions suggests that microaerobic conditions are a prerequisite for their expression.

To evaluate the oxygen concentration response of these genes in $R$. etli, the regulatory regions of norC and nirK were fused to the promoterless uidA reporter gene in plasmid pBBMCS53 (Girard et al. 2000). A 401-bp PCR product that contains the norC upstream region was cloned to construct plasmid pNIC-01 (norC::uidA) (Fig. 2A). A 696-bp PCR product containing the nnr-nirK complete intergenic region, including all anaeroboxes, was cloned in both directions, generating plasmids pNIC-02 (nnrS::uidA) and plasmid pNIC-03 (nirK::uidA) (Fig. 2B). These plasmids were introduced separately into the $R$. etli wild-type strain. As shown in Table 1, only marginal expression of the norC and nirK genes was observed under aerobic conditions. A low-oxygen concentration (1\%) induced nor C expression nearly 50-fold and nirK expression 10-fold. Addition of $100 \mu \mathrm{M}$ sodium nitroprussiate (SNP, a NO-generating agent) or $1.0 \mathrm{mM}$ nitrite to microaerobic cultures increased nor $C$ and nirK microaerobic expression about twofold. In contrast, expression of $n n r S$ was not detected in aerobic and low-oxygen concentration conditions even in the presence of an $\mathrm{N}$ oxide.

To study the participation of FixKf and NnrR as regulators of the expression of the $R$. etli nor $C$ and nirK genes, expression patterns of plasmids pNIC-01 and pNIC-03 in the wildtype and in the fixKf:: $\Omega \mathrm{Km}$ (CFNX637) and nnrR::loxSp (CFNX700) mutant backgrounds were analyzed. The microaerobic expression of norC and nirK is fully dependent on a functional FixKf protein (Fig. 3); in contrast, a differential dependence on NnrR for expression of these genes was observed. While expression of norC is almost abated in an $n n r R$ mutant background (Fig. 3A), the nirK promoter shows only a marginal dependence of NnrR for expression in low-oxygen levels (Fig. 3B). These results indicate that, in addition to FixKf, the presence of $\mathrm{NnrR}$ is indispensable for norC expression. A full expression of nirK was observed in microaerobic cultures in
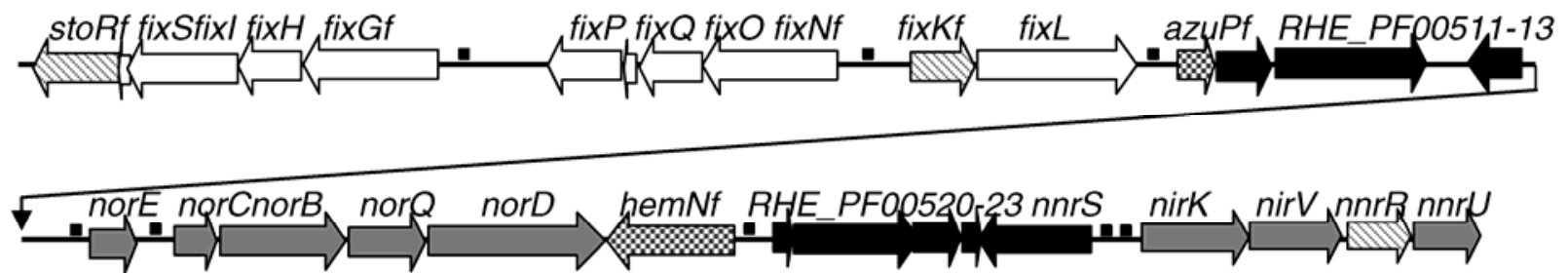

$1 \mathrm{~Kb}$

Fig. 1. Genomic context of the denitrification genes in Rhizobium etli CFN42. The region shown is located from bases 563,249 to 594,052 in plasmid f. Functional categories are indicated according to the annotation in databases: nitrogen fixation (white arrows), denitrification (gray arrows), FNR-type regulators (striped arrows), electron transfer (dotted arrows), hypothetical proteins (black arrows), and putative FNR-binding sites (black squares).

Table 1. Expression of norC::uidA and nirK::uidA gene fusions in Rhizobium etli wild type under free-living conditions

\begin{tabular}{lcccc}
\hline & & \multicolumn{3}{c}{$\beta_{\text {-glucuronidase specific activity }( \pm \text { SD) }}$} \\
\cline { 2 - 4 } Strain & Fusion genotype & Aerobic & $\mathbf{1 \%} \mathbf{O}_{\mathbf{2}}$ & $\mathbf{1 \%}_{\mathbf{2}}+\mathbf{N}$ oxide \\
\hline CE3/pNIC-01 & norC::uidA & $8.4 \pm 0.51$ & $410 \pm 45$ & $741 \pm 49^{\mathrm{b}}$ \\
CE3/pNIC-02 & nnrS::uidA & $\mathrm{ND}^{\mathrm{c}}$ & $\mathrm{ND}^{\mathrm{c}}$ & $\mathrm{ND}^{\mathrm{c}}$ \\
CE3/pNIC-03 & nirK::uidA & $108.0 \pm 11$ & $1,078 \pm 61$ & $2,130 \pm 120^{\mathrm{d}}$ \\
\hline
\end{tabular}

${ }^{a} \beta$-glucuronidase-specific activity ( \pm standard deviation [SD]). In nanomoles per min per milligram of protein; means from at least two independent determinations.

${ }^{\mathrm{b}}$ After $10 \mathrm{~h}$ at $30^{\circ} \mathrm{C}, 100 \mu \mathrm{M}$ sodium nitroprussiate was added to microaerobic cultures and they were incubated $2 \mathrm{~h}$ more.

${ }^{\mathrm{c}} \mathrm{ND}=$ not detected.

${ }^{\mathrm{d}}$ After $10 \mathrm{~h}$ at $30^{\circ} \mathrm{C}, 1.0 \mathrm{mM} \mathrm{NaNO}{ }_{2}$ was added to microaerobic cultures and they were incubated $2 \mathrm{~h}$ more. 
the presence of nitrite and FixKf and NnrR regulators. Complementation of CFNX637 (fixKf::SKm) and CFNX700 (nnrR::loxSp ) mutant strains with plasmids pfixKf (pGHN-06) and pnnrR (pGHN-05), containing the wild-type fixKf and

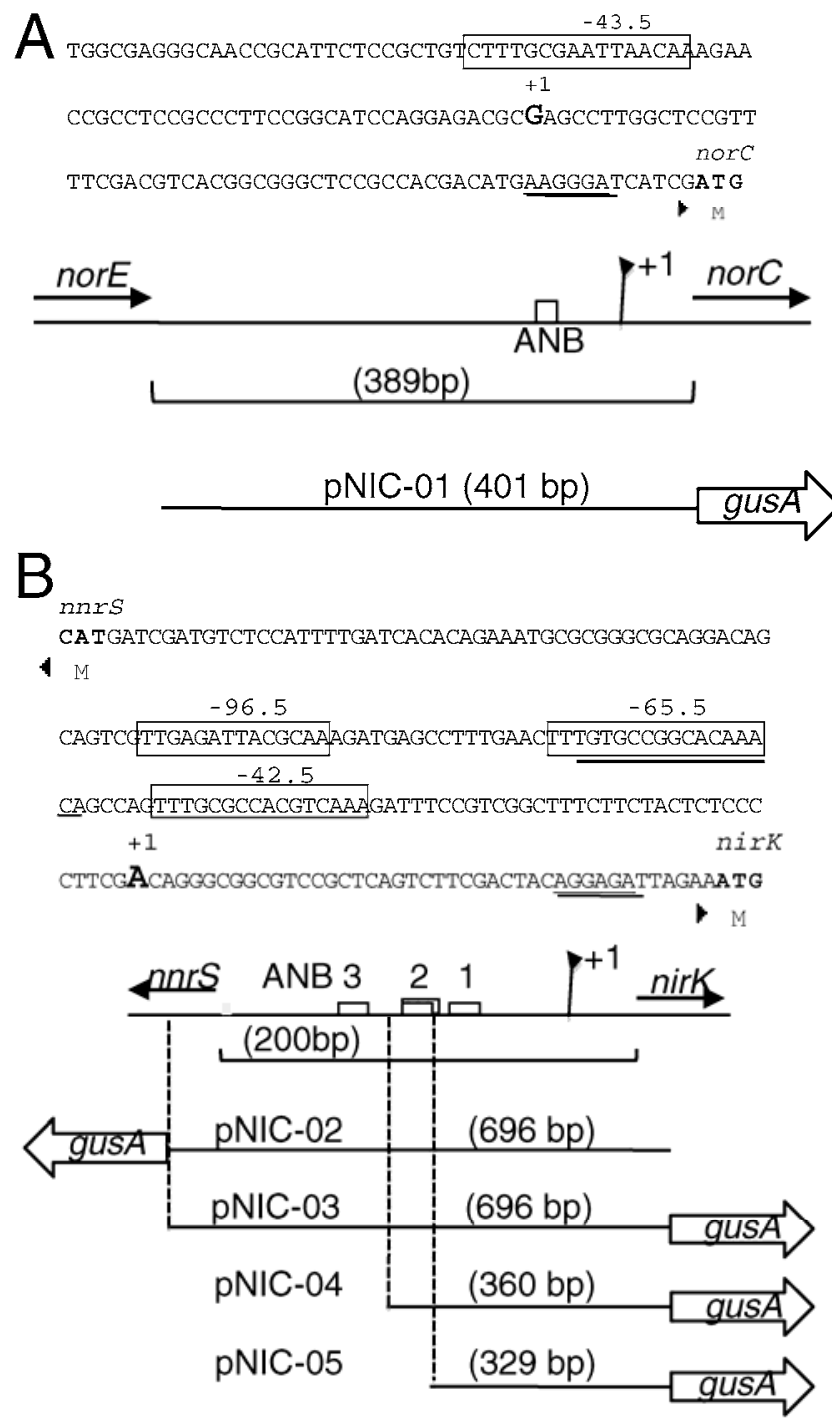

Fig. 2. Regulatory regions of Rhizobium etli norC and nirK genes. A, Sequence and schematic representation of the nor $C$ promoter region and construction of the norC-gus transcriptional fusion in plasmid pBBMCS53. B, Sequence and schematic representation of the nirK promoter region and fragments cloned in plasmid pBBMCS53 to generate nnrS-gus and nirKgus transcriptional fusions. Putative FNR-binding sites are indicated as open boxes labeled ANB; NifA-UAS is underlined and the possible Shine-Dalgarno sequences are double underlined. The transcriptional start sites are indicated as +1 and by bent arrows. Relative positions of the regulatory elements identified and the size of fragments cloned in plasmid pBBMCS53 are indicated. $n n r R$ genes, respectively, under the control of the lacZ promoter, restored the maximal nirK microaerobic expression observed when nitrite is present in the culture (Fig. 3B). Thus, our results clearly show that the induction of nirK and norC in response to $\mathrm{N}$ oxides is dependent on $\mathrm{NnrR}$, which expression is microaerobically mediated by FixKf.

To define the key signal for activation of the $R$. etli NnrR transcriptional regulator, we compared the nirK microaerobic expression in different backgrounds in the presence of nitrite or SNP (Table 2). As observed previously, microaerobic expression of the nirK gene in the wild-type strain increased roughly two times in the presence of nitrite (from $1,078 \pm 61$ to $2,130 \pm 120$ [Table 2]). In contrast, in a nirK mutant (nirK::loxP, CFNX702), a strain unable to reduce $\mathrm{NO}_{2}^{-}$to $\mathrm{NO}$, the level of induction was significantly lower (from 1,009 \pm 75 to $1,288 \pm 41$ [Table 2]). This suggests that reduction of $\mathrm{NO}_{2}{ }^{-}$ to NO is crucial for induction of nirK microaerobic expression. In the presence of SNP, we observed the highest level of nirK expression in both wild-type and nirK mutant (Table 2). Microaerobic expression in a NnrR mutant was not affected by the presence of $\mathrm{NO}_{2}^{-}$or $\mathrm{NO}$ (Table 2). This result indicates, in accordance with Figure 3, that a functional NnrR regulator is a requisite for the response of these genes to the presence of nitrogen oxides. Further evidence to support this interpretation
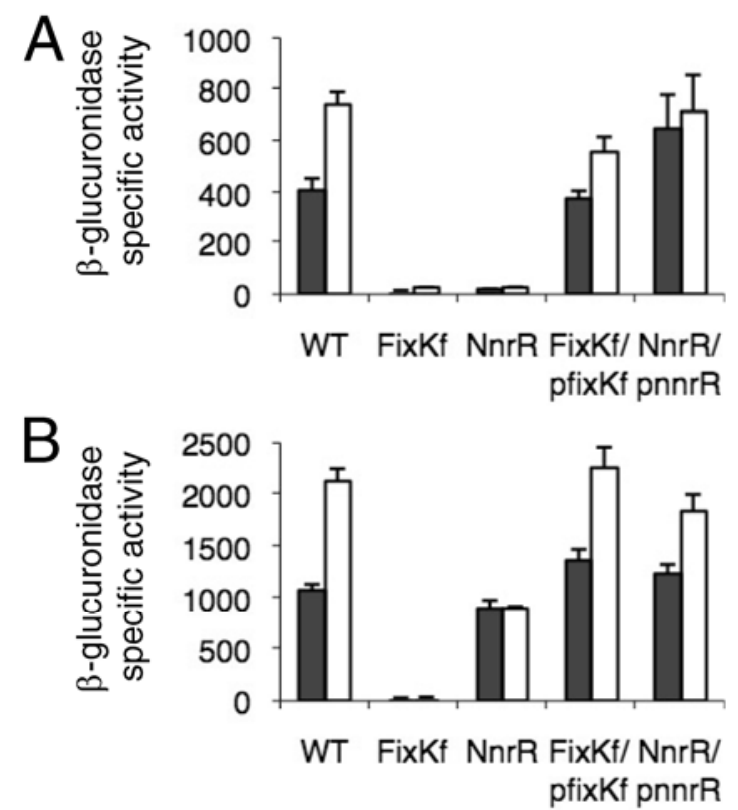

Fig. 3. Microaerobic expression of $\mathbf{A}$, norC and $\mathbf{B}$, nirK genes in different Rhizobium etli strains. Cells were grown microaerobically for $10 \mathrm{~h}$ (gray bars) and the expression was induced (white bars) by incubating $2 \mathrm{~h}$ more with sodium nitroprussiate to a final concentration of $100 \mu \mathrm{M}$ (A) or with nitrite at $1 \mathrm{mM}$ (B). $\beta$-glucuronidase-specific activity is expressed as nanomoles per min per milligram of protein. Data are the mean of two replicas from three independent experiments.

Table 2. Nitric oxide as an environmental signal for the induction of the nirK microaerobic expression mediated by NnrR

\begin{tabular}{|c|c|c|c|c|}
\hline \multirow[b]{2}{*}{ Strain } & \multirow[b]{2}{*}{ Fusion genotype } & \multicolumn{3}{|c|}{$\beta$-glucuronidase specific activity $( \pm \mathrm{SD})^{\mathrm{a}}$} \\
\hline & & $1 \% \mathrm{O}_{2}$ & $1 \% \mathrm{O}_{2}+\mathrm{NaNO}_{2}{ }^{\mathrm{b}}$ & $1 \% \mathrm{O}_{2}+\mathrm{SNP}^{\mathrm{c}}$ \\
\hline CE3/pNIC-03 & nirK::uidA & $1,078 \pm 61$ & $2,130 \pm 120$ & $2,445 \pm 131$ \\
\hline NirK/pNIC-03 & nirK::uidA & $1,009 \pm 75$ & $1,288 \pm 41$ & $1,839 \pm 136$ \\
\hline NnrR/pNIC-03 & nirK::uidA & $894 \pm 88$ & $895 \pm 26$ & $936 \pm 12$ \\
\hline
\end{tabular}

${ }^{a} \beta$-glucuronidase-specific activity ( \pm standard deviation [SD]). In nanomoles per min per milligram of protein; means from at least two independent determinations.

${ }^{\mathrm{b}}$ After $10 \mathrm{~h}$ at $30^{\circ} \mathrm{C}, 1.0 \mathrm{mM} \mathrm{NaNO}_{2}$ was added to microaerobic cultures and they were incubated $2 \mathrm{~h}$ more.

${ }^{\mathrm{c}}$ After $10 \mathrm{~h}$ at $30^{\circ} \mathrm{C}, 100 \mu \mathrm{M}$ sodium nitroprussiate (SNP) was added to microaerobic cultures and they were incubated $2 \mathrm{~h}$ more. 
was obtained by analyzing the microaerobic expression of nirK in a wild-type background with $\mathrm{NaNO}_{2}$ or SNP plus a NO scavenger (c-PTIO). In these experiments, the microaerobic expression of nirK was not affected by the presence of $\mathrm{NaNO}_{2}$ or SNP when 2-(4-carboxyphenyl-4,4,5,5-tetramethylimidazoline-1-oxyl-3-oxide) (cPTIO) was added to the cultures (data not shown). These results clearly demonstrate that NO is the signal required for the induction of the microaerobic expression of nirK mediated by NnrR.

\section{Functional analysis of the putative Fnr-binding sites in the expression of nirK.}

As noted above, we identified three sequences with high similarity to FNR-binding sites in the nnrS-nirK intergenic region. To analyze the functionality and participation of each putative anaerobox in the expression of the nirK operon, DNA fragments containing deletions of the nirK upstream sequence were synthesized by PCR and were fused with a promoterless $\beta$-glucuronidase gene. Plasmids containing transcriptional fusions were introduced separately into different $R$. etli CFN42 derivatives and their transcriptional regulation was studied under microaerobic conditions in comparison with the expression pattern observed with plasmid pNIC-03 (which contains the complete nnrS-nirK intergenic region [Fig. 2B]). A 360-bp-long fragment in plasmid pNIC-04 (nirK::uidA ANB1 and ANB2) carries ANB1 andANB2, while pNIC-05 (nirK::uidA ANB1) only contains ANB1 in a 329-bp-long fragment. The level of nirK microaerobic expression observed in the wild-type strain or in the different mutant backgrounds remained unaffected when ANB3 was deleted, indicating that this sequence is not required for nirK expression (Table 3, compare lines 1 and 2, 4 and 5, 7 and 8, and 10 and 11). The absence of ANB2-induced nirK expression (Table 3 , lines 2 and 3, 5 and 6, 8 and 9, and 11 and 12) suggests that the regulatory region present in pNIC-05 is sufficient for nirK expression and is probably the binding site for either FixKf, NnrR, or both. The increased microaerobic expression of nirK observed when ANB2 is deleted may be due to elimi- nation of multiple FNR sites or ANB2 may be a site recognized by a repressor protein.

Since a potential NifA-binding site overlaps with ANB2, we analyzed nirK expression in a $R$. etli nifA mutant background (CFNX247). Interestingly, mutation of the nifA gene causes an overexpression of nirK even in the presence of the putative NifA-binding site (Table 3, lines 10 to 12), indicating that microaerobic expression of nirK in $R$. etli is subject to both positive and negative regulation, entailing the participation of two Fnr-type regulators (FixKf and NnrR) and a NifA dependent regulator. However, expression of nirK was also augmented $20 \%$ in the NifA mutant in the absence of ANB2 (Table 3 , compare lines 11 and 12). Thus, the participation of several factors governs the expression of nirK in $R$. etli CFN42.

To define more exactly the importance that each anaerobox has as a regulatory site for the expression of nirK, site-specific mutations were introduced in ANB1 (from TTGCG-N4-GTC AA to ATAACG-N4-GTCAA) and ANB2 (from TTGTG-N4$\underline{\text { CACA}} \underline{\mathrm{A}}$ to TTGTG-N4-GATA$\underline{\mathrm{T}}$ ). In each case, changes were designed to interrupt the complementarity in the palindromic regions; moreover, since ANB1 overlaps with the -35 regulatory sequence, changes introduced in this anaerobox were chosen to avoid affecting this region. DNA fragments containing specific mutations were synthesized by PCR and were fused with a promoterless $\beta$-glucuronidase gene. The plasmids constructed (pNIC-06 and pNIC-07) were introduced separately into different $R$. etli CFN42 derivatives and their transcriptional regulation was studied under microaerobic conditions in comparison with the expression pattern observed with plasmid pNIC-03, which contains the complete $n n r S$-nirK intergenic region (Fig. 2B). The microaerobic expression of $n i r K$ is drastically affected when ANB1 is mutated (Table 4). The very low expression levels observed confirm that this region is an essential target site for a positive transcriptional regulator that controls nirK microaerobic expression. Interestingly, when microaerobic expression of nirK is under the control of a regulatory region carrying specific mutations in ANB2 (plasmid pNIC-07), the level of expression is only half that

Table 3. Functional analysis of the nirK regulatory region

\begin{tabular}{|c|c|c|c|}
\hline Strain & Strain genotype & Fusion genotype & $\beta$-glucuronidase specific activity \\
\hline CE3/pNIC-03 & Wild-type & nirK::uidA ANB1,2,3 & $1,078 \pm 61$ \\
\hline CE3/pNIC-04 & Wild-type & nirK::uidA ANB 1,2 & $1,037 \pm 52$ \\
\hline CE3/pNIC-05 & Wild-type & nirK::uidA ANB1 & $1,920 \pm 64$ \\
\hline CFNX637/pNIC-03 & fixKf:: $\Omega \mathrm{Km}$ & nirK::uidA ANB1,2,3 & $35 \pm 12$ \\
\hline CFNX637/pNIC-04 & fix Kf:: $\Omega \mathrm{Km}$ & nirK:: uidA ANB 1,2 & $51 \pm 23$ \\
\hline CFNX637/pNIC-05 & fixKf:: $\Omega \mathrm{Km}$ & nirK::uidA ANB1 & $59 \pm 7$ \\
\hline CFNX700/pNIC-03 & nnrR::loxSp & nirk::uidA ANB1,2,3 & $886 \pm 59$ \\
\hline CFNX700/pNIC-04 & $n n r R:: \operatorname{lox} \mathrm{Sp}$ & nirK::uidA ANB1,2 & $867 \pm 63$ \\
\hline CFNX700/pNIC-05 & $n n r R:: l o x \mathrm{Sp}$ & nirK::uidA ANB1 & $2,064 \pm 22$ \\
\hline CFNX247/pNIC-03 & nif $A_{4}:: \Omega S p$ & nirK::uidA ANB1,2,3 & $1,834 \pm 73$ \\
\hline CFNX247/pNIC-04 & nif $A_{\Delta}:: \Omega S p$ & nirK::uidA ANB1,2 & $1,859 \pm 108$ \\
\hline CFNX247/pNIC-05 & nif $A_{4}:: \Omega S p$ & nirK::uidA-ANB1 & $2,372 \pm 53$ \\
\hline
\end{tabular}

${ }^{a} \beta$-glucuronidase-specific activity ( \pm standard deviation). In nanomoles per min per milligram of protein; means from at least three independent determinations.

Table 4. Mutational analysis of the FNR sites in the nirK regulatory region

\begin{tabular}{|c|c|c|c|c|}
\hline \multirow[b]{2}{*}{ Strain } & \multirow[b]{2}{*}{ Fusion genotype } & \multirow[b]{2}{*}{$\mathbf{A N B}^{\mathrm{a}}$} & \multicolumn{2}{|c|}{ Expression level $^{\text {b }}$} \\
\hline & & & Aerobic & Microaerobic \\
\hline CE3/pNIC-03 & nirK::uidA & $1,2,3$ & $108 \pm 11$ & $1,078 \pm 61$ \\
\hline CE3/pNIC-06 & nirK::uidA & $1 \mathrm{~m}^{\mathrm{c}}, 2,3$ & $12 \pm 4$ & $38 \pm 3$ \\
\hline CE3/pNIC-07 & nirK::uidA & $1,2 \mathrm{~m}^{\mathrm{d}}, 3$ & $67 \pm 5$ & $510 \pm 10$ \\
\hline
\end{tabular}


found when nirK expression is driven by a wild-type regulatory region (Table 4). Therefore, we hypothesize that ANB2 is also a target sequence for a positive regulator necessary for attaining the highest microaerobic expression of nirK.

\section{$R$. etli nirK and nor $C$ encode functional reductases.}

Previously, we reported that, in $R$. etli CE3, the nirK gene encodes a functional nitrite reductase. In contrast to the $R$. etli

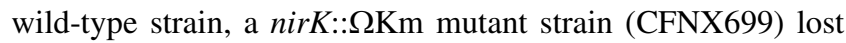
the methyl viologen (MV)-dependent Nir activity and the capacity to consume nitrite from the medium in anaerobic cultures (Bueno et al. 2005). In this work, we demonstrate that disruption of nirK with a $\Omega \mathrm{Km}$ interposon exerts a polar effect on the downstream genes in the operon, including the gene encoding the NnrR transcriptional regulator. To avoid polarity effects on $n n r R$, a new nirK::loxPSp allele was generated. From this, an in-phase knock-out allele was derived (nirK::loxP) by Cremediated excision of the spectinomycin (Sp) cassette (strain CFNX702, discussed below). To evaluate the functionality of the reductase encoded by the $R$. etli nirK gene, nitrite reductase activity was determined in cell extracts from the wild-type and the nirK::loxP (CFNX702), fixKf::SKm (CFNX637), and nnrR::loxPSp (CFNX700) mutant strains grown microaerobically (Fig. 4). Nir activity was only detected in the wild-type strain.

Since specific mutations in the nirK regulatory sites (ANB1 and ANB2) affect gene expression, we performed a complementation analysis in the nirK mutant to ascertain if these mutations also have an effect on the Nir activity. To that end, three different plasmids were constructed: i) pnirK-RRWt (pGHN01 ), in which the expression of nirK is under the control of the wild-type regulatory region; ii) pnirK-ANB2m (pGHN-03), in which the nirK regulatory region carried site-specific mutations in ANB2; and iii) pnirK-ANB1m (pGHN-02), in which the ANB1 was mutated. Wild-type Nir activity was restored upon introduction of plasmids pGHN-01 and pGHN-03 in the nirK mutant (Fig. 4). In contrast, plasmid pGHN-02, with ANB1 mutated, was unable to restore this activity. These data are consistent with a possible promoter located in ANB1 that is necessary for full expression of nitrite reductase activity.

As mentioned, a mutation in $n n r R$ provokes a reduction of just 50\% in nirK expression (Fig. 3B). Interestingly, Nir enzymatic activity was not detected in this background (Fig. 4), suggesting that NnrR is controlling other genes needed for Nir

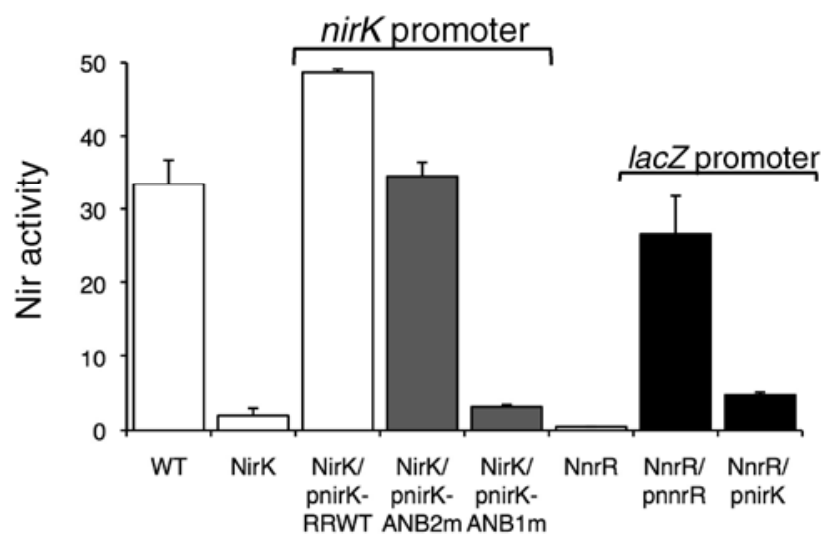

Fig. 4. Methyl viologen-dependent nitrite reductase activity in free-living conditions of both the nirK or $n n r R$ mutant derivatives carrying plasmids that express $n i r K$ or $n n r R$ controlled by different promoters, i.e., wild-type promoters (white bars), mutated promoters (gray bars), and constitutive promoters (black bars). Nir activity is expressed as nanomoles $\mathrm{NO}_{2}^{-}$consumed per $\mathrm{h}$ per milligram of protein. Data show the mean of three independent experiments assayed three times. Error bars are indicated. activity. If this was the case, no Nir enzymatic activity should be seen in a $n n r R$ mutant, even under conditions that restore full nirK expression. To substantiate this, two constitutive expression plasmids were generated, pnirK and pnnrR (pGHN-04 and pGHN-05, respectively), putting the nirK and the $n n r R$ coding regions under the control of the $l a c Z$ promoter. Introduction of pGHN-04 in the $n n r R$ mutant background failed to restore Nir activity, while wild-type activity was recovered in the $n n r R$ mutant complemented with pGHN-05 (Fig. 4). These data support our interpretation that additional genes, controlled by $n n r R$, are required for full expression of Nir enzymatic activity.

\section{$R$. etli responds to nitric oxide}

by the expression of nirK and nor $C$ genes.

The in vivo relevance of the functions encoded by the nirK and $n o r C$ genes can be further ascertained by exploring the response of the corresponding mutants to both nitrite and to nitric oxide generators, such as SNP. Although none of the mutants described here affect growth under microaerobic conditions (Fig. 5A), the presence of $1 \mathrm{mM} \mathrm{NaNO}_{2}$ drastically affects this capacity, both in the wild-type strain and in the nor $C$ mutant and, to a lesser extent, in the $n n r R$ mutant. Both the nirK and the $n n r R$ mutants displayed a marked inhibition of growth in the presence of nitrite upon complementation with the corresponding genes, indicating that nitrite sensitivity in the wild-type strain is due to the presence of NirK and NnrR proteins (Fig. 5B). This sensitivity is most likely due to the role of both proteins, either directly or indirectly, to produce nitric oxide. To evaluate this possibility, levels of NO production and consumption were evaluated in the wild type and in the nirK mutant with a nitric oxide electrode (discussed below). As shown in Table 5, high levels of NO production were seen in the wild type, while in the nirK mutant, levels of this metabolite were almost negligible.

Significant levels of NO consumption were detected in the wild type. This activity is due to the product of norC, since levels of consumption were virtually undetectable in the corresponding mutant. Moreover, the norC mutant showed levels of NO production twice as high as that seen in the wild type. These data allow us to predict that the nor $C$ mutant should be hypersensitive to the effects of a nitric oxide generator such as SNP and to nitrite as well. As expected, the presence of $100 \mu \mathrm{M}$ SNP in the culture severely affects the microaerobic growth of the norC (CFNX701) and nnrR (CFNX700) mutants, while the growth of the wild type was relatively resistant to SNP addition (Fig. 5C). Confirmation of the in vivo role of NorC in detoxifying the NO produced from nitrite was achieved by growth tests under microaerobic conditions of both the wild type and the norC mutant in the presence of sublethal concentrations of $\mathrm{NaNO}_{2}(30 \mu \mathrm{M})$. The wild-type strain was still able to grow microaerobically in the presence of $30 \mu \mathrm{M} \mathrm{NaNO}$, while the norC mutant failed to grow in this condition (Fig. 5D). These data clearly indicate that the product of $n o r C$ is required in vivo to detoxify $\mathrm{NO}$ and that the balance between the activities of NirK and NorC determine the level of tolerance to NO.

\section{Symbiotic expression of the nirK and norC genes.}

Ex planta, expression of both nirK and nor $C$ genes require low-oxygen conditions. This expression is further enhanced by the presence of a nitrogen oxide. To test if these genes are also expressed in nodules, common bean plants (Phaseolus vulgaris) were inoculated with either the wild-type, nirK, or norC mutant strains and were watered with or without nitrate.

The expression of nirK and norC genes in nodule was analyzed by reverse transcription-polymerase chain reaction (RTPCR). RNA was purified from nodules of bean plants that were inoculated with $R$. etli wild-type strain. The presence of a cDNA 
product corresponding to nirK and norC confirm that these genes are expressed in bean nodules (data not shown). Measurements of Nir activity in cell extracts from bean nodules revealed that the nitrite reductase activity in the wild-type nodules was about 4.8 times higher than that observed in extracts from nodules formed by the nirK mutant $(95 \pm 6.3$ vs. $19.5 \pm 0.7 \mathrm{nmol}$ $\mathrm{NO}_{2}{ }^{-}$consumed per milligram of protein per $\mathrm{h}$, respectively). Only marginal increases in Nir activity were observed in plants treated with $4 \mathrm{mM} \mathrm{KNO}_{3}$ for 12 days before harvesting. Thus, in $R$. etli the symbiotic condition per se is sufficient to achieve a maximal activity of the reductase encoded by the nirK gene.

To evaluate the potential contribution of the bacterial microsymbiont to NO production in bean plants, the proportion of Lb-NO complexes in nodules was quantified by UV-visible absorbance spectroscopy. To this end, bean plants were inoculated with wild type, nirK, or norC mutant strains and were watered with a solution containing nitrate at 14 days postinoculation (dpi). The proportion of Lb-NO complexes formed in nodules from plants cultivated without $\mathrm{KNO}_{3}$ was approximately 15 to $20 \%$, irrespective of the strain used for inoculation (Table 6). However, Lb-NO formation increased to $64 \%$ with the application of nitrate in wild-type nodules and up to
95\% in plants inoculated with the nor $C$ mutant. The marked increase in Lb-NO formation in the norC mutant may be due to impaired elimination of $\mathrm{NO}$ in these nodules, indicating an important role of the microsymbiont in protection from NO. Moreover, null mutations in the nirK gene prevent nitrateinduced increase in the formation of Lb-NO complexes, which remained at low levels (15 to $20 \%$ ). This indicates that bacterial nitrite reductase is an important contributor to the formation of NO in nodules.

None of the mutants employed affected nitrogenase-specific activity in the absence of nitrate (Table 6). Nitrate induces a threefold decline in nitrogenase-specific activity for both the wild type and the norC mutant; in contrast, the nitrogenasespecific activity in nodules induced by the nirK mutant did not show a nitrate-induced decline (Table 6). This result may be explained by the reduced amount of Lb-NO present in these nodules, as compared with the wild type and the norC mutant.

\section{DISCUSSION}

In this work, we demonstrate that, in $R$. etli CFN42, the nirK and norCBQD genes located on plasmid pCFN42f encode a
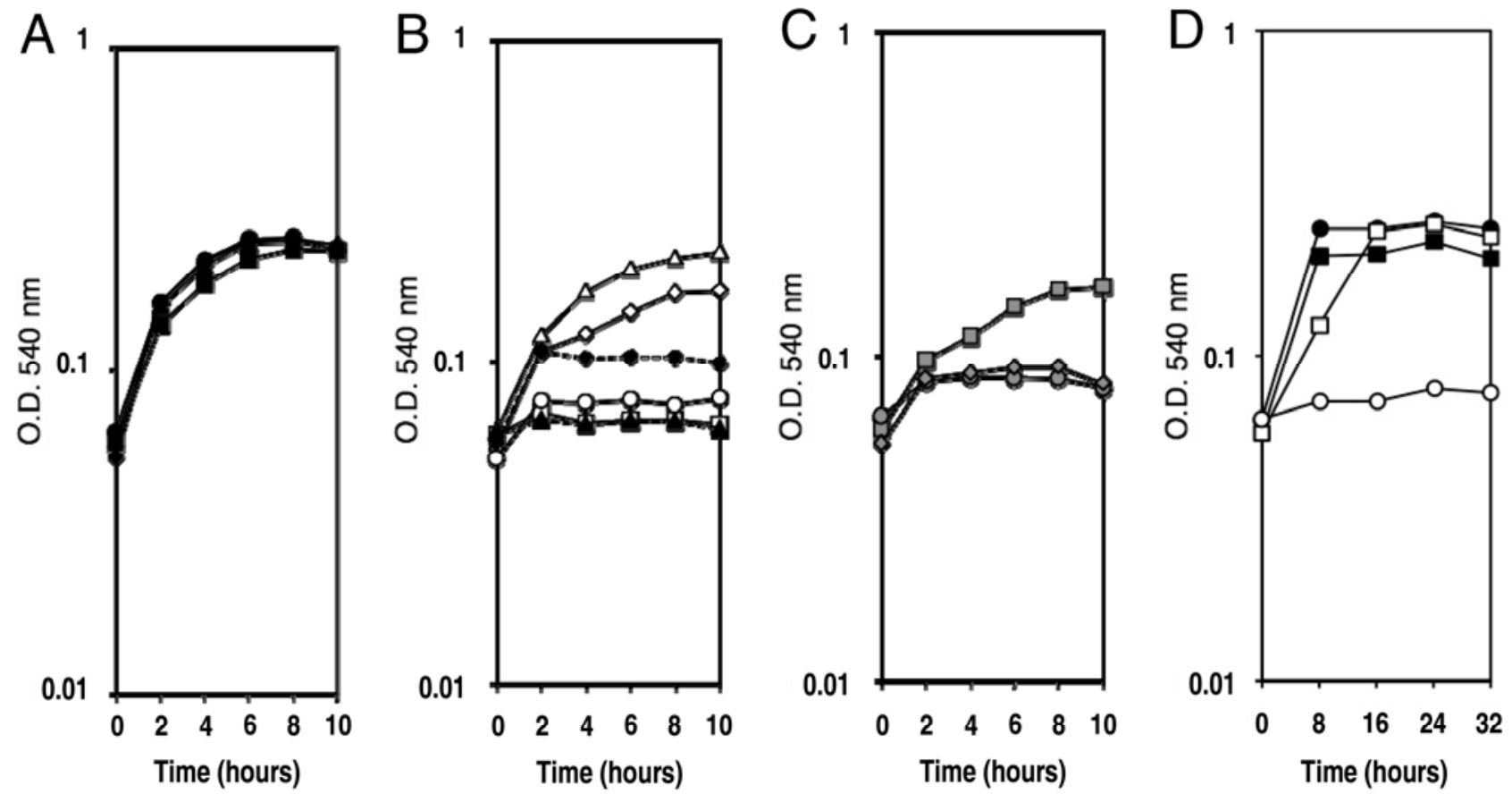

Fig. 5. Effect of nitrogen oxides on the microaerobic growth of Rhizobium etli. A, B, and $\mathbf{C}$, Cells were cultivated in minimal medium at $30^{\circ} \mathrm{C}$ for $10 \mathrm{~h}$ or $\mathbf{D}$, $32 \mathrm{~h}$ under $\mathbf{A}$, microaerobic conditions or $\mathbf{B}$, microaerobic conditions plus $1.0 \mathrm{mM} \mathrm{NaNO}$, $\mathbf{C}$, plus $100 \mu \mathrm{M}$ sodium nitroprussiate (SNP), or $\mathbf{D}$, plus $30 \mu \mathrm{M}$ $\mathrm{NaNO}_{2}$. Squares indicate growth of wild-type strain under microaerobic conditions $(\mathbf{\square})$, plus $\mathrm{NaNO}_{2}(\square)$, or plus SNP ( $\square$ ); triangles indicate growth of nirK mutant strain CFNX702 under microaerobic conditions $(\boldsymbol{\Delta})$, plus $\mathrm{NaNO}_{2}(\triangle)$, or plus SNP $(\Delta)$. Growth of complemented nirK mutant strain CFNX702 with plasmid pGHN-04 under microaerobic conditions with $\mathrm{NaNO}_{2}$ is indicated by -- $\mathbf{\Delta}$--. Circles indicate growth of norC mutant strain CFNX701 under microaerobic conditions $(\bullet)$, plus $\mathrm{NaNO}_{2}(\mathrm{O})$, or plus SNP $(\odot)$. Diamonds indicate growth of $n n r R$ mutant strain CFNX700 under microaerobic conditions $(\diamond)$, plus $\mathrm{NaNO}_{2}(\diamond)$, or plus SNP $(\diamond)$. Growth of complemented $n n r R$ mutant strain CFNX700 with plasmid pGHN-05 under microaerobic conditions with $\mathrm{NaNO}_{2}$ is indidcated by -- --.

Table 5. Nitric oxide production and consumption in Rhizobium etli

\begin{tabular}{llcc}
\hline Strain & Genotype & NO production ${ }^{\mathbf{a}}$ & NO consumption $^{\mathbf{b}}$ \\
\hline CE3 & Wild-type & $219.0 \pm 15$ & $42 \pm 4$ \\
CFNX702 & nirK::loxP & $3.0 \pm 0.1$ & Not measured \\
CFNX701 & norC::loxPSp & $557.2 \pm 43$ & Not detected \\
\hline
\end{tabular}

${ }^{\mathrm{a}} \mathrm{NO}$ produced in free-living cells after the addition of $30 \mu \mathrm{l}$ of $50 \mathrm{mM} \mathrm{NaNO}_{2}$, expressed in nanomoles of NO per h per milligram of protein. Means from at least two independent determinations.

${ }^{\mathrm{b}} \mathrm{NO}$ consumed in free-living cells after the addition of $100 \mu \mathrm{l}$ of a saturated NO solution $(1.91 \mathrm{mM})$, expressed in nanomoles of NO per h per milligram of protein. Means from at least two independent determinations. 
functional $\mathrm{Cu}$-containing nitrite reductase and a cytochrome $c$ type nitric oxide reductase, respectively. Previously, we demonstrated that $R$. etli fails to grow anaerobically with $\mathrm{KNO}_{3}$ and lacks nitrate reductase activity (Bueno et al. 2005). In addition, we confirm by genome analysis that $R$. etli lacks the nitrate and the nitrous oxide reductases. As a consequence of the low efficiency of energy coupling using nitrite reduction, $R$. etli CFN42 displays a poor anaerobic growth at the expense of nitrite. Therefore, we propose that, in R. etli CFN42, the accumulation of toxic levels of nitric oxide is prevented by the NO reductase, acting in concert with the $\mathrm{NO}_{2}$ reductase.

FixK and NnrR, two members of the CRP/FNR family, have been described as regulatory proteins for the expression of genes encoding reductases involved in denitrification. FixK is needed for activation of these genes under oxygen-limited conditions, while the response to the presence of $\mathrm{N}$ oxide depends of NnrR (Bedmar et al. 2005; Hartsock and Shapleigh 2010; Mesa et al. 2003; Robles et al. 2006). Recently, the participation of additional regulatory proteins for expression of these genes was reported. Among them, NifA is required in $B$. japonicum for a full expression of nirK, norC, and napE genes (Bueno et al. 2010), while Agrobacterium tumefaciens employs ActR and FnrR to control nirK and norC expression (Baek et al. 2008).

The novel operon arrangement reported here for nirK and one of its transcriptional regulators $(n n r R)$ differentiates the way that $R$. etli regulates these genes. In the nor $C$ and nirK regulatory regions, we identified class II promoters in which an FNR regulator activates expression in response to low-oxygen concentrations (Wing et al. 1995). Expression analysis clearly shows that a functional FixKf protein is entirely required to activate, under low-oxygen conditions, nirK and norC promoters, while response to $\mathrm{N}$ oxides under microaerobiosis is mediated by NnrR. A differential dependence for NnrR was observed. Full expression of nor $C$ in response to $\mathrm{N}$ oxides under microaerobiosis requires the presence of FixK and NnrR. In contrast and similar to that described in B. japonicum (Mesa et al. 2003), microaerobic expression of nirK is still observed in an $n n r R$ mutant background. Since $n i r K$ and $n n r R$ are part of a single operon, this has the important consequence that NnrR controls its own $\mathrm{N}$ oxide-dependent expression. The signal required for the induction of the microaerobic expression of nirK mediated by NnrR is the production of NO. This regulatory arrangement in $R$. etli ensures that expression of nirK and $n o r C$ is coupled to facilitate NO detoxification.

Three putative FNR sites were found in the nirK regulatory region. The observation that a nirK regulatory region with only ANB1 is highly expressed supports the idea that, in $R$. etli, the presence of more than one anaerobox has a repressive effect, as reported in other systems (Green et al. 2001). In addition, both ANB1 and ANB2 are target sites for other positive regulators, since a low expression level was observed when point mutations were introduced. Therefore, in $R$. etli CFN42, activation of nirK depends on FixKf, low oxygen conditions and the FNR site ANB1. For maximum nirK expression, nnrR needs to be activated by NnrR when NO is present. Under these conditions, NnrR also activates norC to prevent NO accumulation. The removal of FixKf results in the loss of nirK expression, whereas in a $n n r R$ mutant, levels of $n i r K$ are just halved. Interestingly, this mutant lacks any nitrite reductase activity. The dependence on NnrR for complete enzymatic activity may imply that this protein regulates some additional elements necessary for the nitrite reductase activity.

Additional members of the NnrR regulon in $R$. etli may be $c y s G$ and $a z u P f$. It was reported that in, $R$. etli CE3, the siroheme cofactor (product of the CysG activity) is required for nitrite reductase activity (Tate et al. 1997). The presence of a putative FNR-binding site in the $R$. etli cys $G$ regulatory region (L. Girard, unpublished data) opens the possibility that this gene is also a NnrR target gene. Preliminary data from our laboratory suggest that the $a z u P f$ gene, encoding a blue copper pseudoazurin (a possible electron donor for the nitrite reductase), is also part of the NnrR regulon.

The structuring of regulatory circuits for controlling nirK and norC shows similarities between rhizobiales but also important differences. Common to all systems is the requirement of $n n r R$. A remarkable difference between Agrobacterium spp. and both $R$. etli and B. japonicum is the role of FixK as a regulator for nirK expression. Unlike $R$. etli and B. japonicum, FixK is not needed in A. tumefaciens for control of nirK, which is controlled by FnrN and ActR instead (Baek et al. 2008). Experiments to determine the involvement of ActR as an additional regulator of nirK in $R$. etli are considered for the future.

At very low oxygen concentrations, denitrification genes in B. japonicum need NifA for maximal expression (Bueno et al. 2010). In contrast, this regulator in $R$. etli has a negative effect on the expression of the nirK operon. In both cases, NifA appears to modulate by a factor of two the level of expression of nirK. It has been reported that the presence of both nitrite and a functional nitrite reductase affects oxygen respiration when nondenitrifying bacteria are growing in low-oxygen conditions (Toffanin et al. 1996). Furthermore, the binding of nitric oxide to cytochrome $c$ oxidase can inhibit its activity (Brown and Cooper 1994). Therefore, we hypothesize that modulation of the nirK operon by NifA can be used in nondenitrifying bacteria, such as $R$. etli, to protect its symbiotic cytochrome oxidase operating during nitrogen fixation.

Nitric oxide participates in diverse plant processes as a signaling molecule. Several studies have shown the production of NO during different stages of the legume-rhizobia symbiosis (Baudouin et al. 2006; Cueto et al. 1996; Sánchez et al. 2010; Shimoda et al. 2005). Nevertheless, the exact source of NO in nodules is still controversial, with proposals that nodular NO comes as a product of bacterial denitrifying metabolism (Meakin et al. 2007; Sánchez et al. 2010) or may also be produced in plant root tissue from arginine via an unidentified NOS-like enzyme (Baudouin et al. 2006). In addition, in plant

Table 6. Nitrogenase activity and proportion of nitrosylleghemoglobin (Lb-NO) in bean nodules formed by Rhizobium etli wild-type, nirK, and norC strains

\begin{tabular}{|c|c|c|c|c|c|c|}
\hline \multirow[b]{2}{*}{ Strain } & \multirow[b]{2}{*}{ Genotype } & \multicolumn{2}{|c|}{$-\mathrm{KNO}_{3}$} & \multirow[b]{2}{*}{$\mathbf{L b}^{-N^{\prime}}{ }^{\mathbf{b}}$} & \multicolumn{2}{|c|}{$+\mathrm{KNO}_{3}$} \\
\hline & & $14 \mathrm{dpi}^{\mathrm{a}}$ & $25 \mathrm{dpi}^{\mathrm{a}}$ & & $25 \mathrm{dpi}^{\mathrm{a}}$ & Lb-NO $^{b}$ \\
\hline CE3 & Wild-type & $38 \pm 11$ & $23 \pm 8^{*}$ & $20 \pm 3$ & $13 \pm 3^{*}$ & $66 \pm 3$ \\
\hline CFNX702 & nirK::loxP & $30 \pm 13$ & $25 \pm 5$ & $18 \pm 3$ & $31 \pm 11$ & $20 \pm 2$ \\
\hline CFNX701 & norC: $: \operatorname{lox} P S p$ & $35 \pm 8$ & $31 \pm 8^{*}$ & $15 \pm 2$ & $13 \pm 5^{*}$ & $90 \pm 5$ \\
\hline
\end{tabular}

\footnotetext{
${ }^{a}$ Nitrogenase-specific activity determined at 14 and 25 days postinoculation (dpi), expressed in micromole ethylene per gram of nodule per h. Data are the average of nine control plants $\left(-\mathrm{KNO}_{3}\right)$ or nine plants watered with $4 \mathrm{mM} \mathrm{KNO} 3$ for 12 days $\left(+\mathrm{KNO}_{3}\right)$. Asterisks $(*)$ indicate that the means of the samples are different from the control plants at the 0.05 level $(P=0.05$, Student's $t$-test).

${ }^{b}$ Percentage of Lb-NO complexes was determined by UV-Vis spectra. Nodules were isolated at 25 dpi from control plants or plants watered with $\mathrm{KNO}_{3}$ for 12 days. Data are the average of two independent assays.
} 
cells, NO can be produced from nitrate via both nonenzymatic and enzymatic pathways, i.e., those catalyzed by nitrate reductase (Meyer et al. 2005) or by the plasma membrane-bound nitrite NO reductase (Stöhr et al. 2001). In the root nodules, as a result of the reducing conditions needed for nitrogen fixation, formation of the Lb-NO complex is believed to occur as a result of the reduction of exogenous nitrate. In this condition, NO binding may inhibit the oxygen-carrying activity of the leghemoglobin. It has also been observed that, as a result of the exposition of root nodules to high concentrations of nitrate, results in an increased yield of Lb-NO with a concomitant decrease in acetylene (ethylene) reducing activity. Thus, formation of Lb-NO as a result of nitrate reduction appears to have deleterious effects on the functional activity of root nodules (Mathieu et al. 1998; Sánchez et al. 2010).

In this study, we found that levels of Lb-NO in bean plants exposed to nitrate are increased in a nor $C$ mutant but decreased in a nirK mutant. These results are consistent with production of NO from the bacterial nitrite reductase and its elimination by the bacterial nitric oxide reductase in bean nodules. Important as the bacterial contribution to $\mathrm{NO}$ metabolism seems to be, it should be pointed out that it is not the only route to NO production. Even in a nirK mutant, low levels of Lb-NO were seen, indicating that other routes of unknown origin are participating in NO production. In contrast to our observations, in soybean nodules formed by nirK and norC mutants, the maximal formation of Lb-NO complexes require a physiological stress condition such as flooding in addition to nitrate. In this condition, nitrogenase activity in nirK nodules is not affected (Sánchez et al. 2010).

Interestingly, in bean nodules, the nitrate-induced decline in nitrogenase-specific activity observed in both the wild type and the norC mutant was not detected in the nirK mutant. This can be explained by the high levels of Lb-NO observed in the former two strains and the reduced levels of Lb-NO in the latter strain. Thus, these results reveal the commitment of these reductases to safeguard nitrogenase activity in $R$. etli from toxic levels of nitrogen reactive species.

Thus, results from our present work clearly demonstrate that, in $R$. etli CFN42, the product of nor $C$ is required in vivo to detoxify $\mathrm{NO}$ and that the balance between the activities of NirK and NorC determine the level of tolerance to NO. The particular genomic arrangement in $R$. etli of nirK and $n n r R$ genes in a single operon suggests that NnrR controls its own expression in response to NO. Nitrite reductase activity and norC expression are totally dependent on NnrR. Therefore, gene expression in response to NO is tightly regulated in this bacterium to prevent deleterious effects by the expression of the nitrite reductase.

\section{MATERIALS AND METHODS}

\section{Bacterial strains, plasmids, and growth conditions.}

The bacterial strains and plasmids used are listed in Table 7. Rhizobium strains were grown at $30^{\circ} \mathrm{C}$ in $\mathrm{PY}$ rich medium (Noel et al.1984) or in Y minimal medium (MMY) with succinate $(10 \mathrm{mM})$ and ammonium chloride $(10 \mathrm{mM})$ as carbon and nitrogen sources, respectively (Bravo and Mora 1988). Escherichia coli strains were grown at $37^{\circ} \mathrm{C}$ in Luria-Bertani medium. Antibiotics were added at the following concentrations: carbenicillin, $100 \mu \mathrm{g} \mathrm{ml}^{-1}$ (E. coli); streptomycin (Sm), $200 \mu \mathrm{g}$ $\mathrm{ml}^{-1}$ (R. etli); gentamicin $(\mathrm{Gm}), 15 \mu \mathrm{g} \mathrm{ml} \mathrm{m}^{-1}$ (E. coli and $R$. etli); kanamycin $(\mathrm{Km}) 30 \mu \mathrm{g} \mathrm{ml}^{-1}$ (for both E. coli and R. etli); nalidixic acid $20 \mu \mathrm{g} \mathrm{ml}^{-1}$ (R. etli); and spectinomycin (Sp), 100 $\mu \mathrm{g} \mathrm{ml}^{-1}$ (E. coli or $R$. etli). When required, sucrose was added at $12.5 \%$ (wt/vol). For detection of $\beta$-galactosidase and $\beta$-glucuronidase activity, 5-bromo-4-chloro-3-indolyl- $\beta$-D-galactoside and 5-bromo-4-chloro-3-indolyl- $\beta$-D-glucuronide, respectively, were used in plates at a concentration of $20 \mu \mathrm{g} \mathrm{ml}^{-1}$.

For growth under microaerobic conditions, cultures were grown to mid-exponential phase in PY medium. Cells were collected by centrifugation, were washed with sterile MMY, and were concentrated 100-fold. MMY containing $10 \mathrm{mM}$ of succinate and $10 \mathrm{mM}$ of ammonium chloride as carbon and nitrogen sources $(20 \mathrm{ml})$ were inoculated with these suspensions at an initial optical density at $540 \mathrm{~nm}$ of 0.05 . Cultures were incubated in 150-ml bottles closed with an airtight stopper and were flushed with several volumes of an oxygen and $\operatorname{argon}(1: 99, \mathrm{vol} / \mathrm{vol})$ mixture. Cultures were grown with shaking (200 rpm) for $10 \mathrm{~h}$ at $30^{\circ} \mathrm{C}$ (Granados-Baeza et al. 2007). When needed, cells were cultivated with $10 \mathrm{mM} \mathrm{KNO}$, 30 $\mu \mathrm{M}$ or $1.0 \mathrm{mM} \mathrm{NaNO}{ }_{2}, 100 \mu \mathrm{M}$ SNP or $1 \mathrm{mM}$ cPTIO (Invitrogen, Carlsbad, CA, U.S.A.); induction experiments were carried out by adding the corresponding $\mathrm{N}$ oxide to microaerobic cultures and incubating for $2 \mathrm{~h}$ more.

\section{Microbiological and recombinant DNA methods.}

Total and plasmid DNA isolation, digestion with restriction enzymes, cloning, agarose gel electrophoresis, and E. coli transformation were performed using standard protocols (Sambrook et al. 1989). Enzymes used for DNA restriction and modification were purchased from either Invitrogen or Fermentas (Vilnius, Lithuania) and were used according to the instructions of the manufacturer.

Conjugative transfer of plasmids from E. coli to Rhizobium spp. was done routinely by triparental crosses, using either pRK2013 or pRK2073 as helpers. For determination of plasmid profiles, a modified Eckhardt procedure was used (Hynes and McGregor 1990).

For Southern hybridizations, DNA was digested with appropriate restriction enzymes, electrophoresed in $1 \%$ (wt/vol) agarose gels, and blotted onto nylon (Hybond $\mathrm{N}+$ ). Hybridization was carried out under high stringency conditions using Rapidhyb buffer (Amersham, Bucks, U.K.). Specific probes were normally obtained by PCR and were labeled with $\alpha^{32}$ P-CTP by random priming, using Amersham's Rediprime system.

\section{Enzymatic assays.}

Nitrate reductase and nitrite reductase activities were determined by a colorimetric MV-dependent assay (Bueno et al. 2005; Delgado et al. 2003; Mesa et al. 2003). To prepare freeliving cell suspensions, $20 \mathrm{ml}$ of microaerobic cultures were spun down at $8,000 \mathrm{rpm}, 4^{\circ} \mathrm{C}$ for $10 \mathrm{~min}$, were washed in 50 $\mathrm{mM}$ Tris- $\mathrm{HCl}$ buffer until no nitrite was detected, and were resuspended in $1.2 \mathrm{ml}$ of the same buffer. For determinations of Nir activity, aliquots of $200 \mu \mathrm{l}$ of cell suspension (1 to $3 \mathrm{mg}$ of protein) were added to a reaction mixture containing 20 $\mathrm{mM}$ Tris- $\mathrm{HCl}$ buffer ( $\mathrm{pH} 7.5), 0.2 \mathrm{mM} \mathrm{KNO}_{2}$, and $0.4 \mathrm{mM}$ MV. The reaction was started by the addition of $50 \mu \mathrm{l}$ of freshly prepared sodium dithionite solution $(30 \mathrm{mg} / \mathrm{ml})$ in 300 $\mathrm{mM} \mathrm{NaHCO}$. After incubation for $20 \mathrm{~min}$ at $30^{\circ} \mathrm{C}$, the reaction was stopped by shaking, until the samples had lost their blue color. Control reactions were run at the same time, but the sodium dithionite was oxidized at the start of the reaction. Nitrate reductase reaction mixture contained $20 \mathrm{mM}$ Tris- $\mathrm{HCl}$ buffer (pH 7.5), $20 \mathrm{mM} \mathrm{KNO}_{3}, 0.4 \mathrm{mM}$ of MV, and $200 \mu \mathrm{l}$ of cell suspension (1 to $3 \mathrm{mg}$ of protein). The reaction was started by addition of $50 \mu \mathrm{l}$ of freshly prepared sodium dithionite solution $\left(8 \mathrm{mg} \mathrm{ml}^{-1}\right)$ in Tris- $\mathrm{HCl}$ buffer. After incubation for 30 min at $30^{\circ} \mathrm{C}$, the reaction was stopped by vigorous shaking until the samples had lost their blue color. Nitrite was estimated by the diazotation reaction, adding equal amounts of sulphanilamide, naphthylethylene diamine dyhydrochloride, and cell suspension. This mixture was then incubated at room 
temperature for $20 \mathrm{~min}$, measuring the absorbance at $450 \mathrm{~nm}$ of each sample. The amount of nitrite was determined from a standard curve of known nitrite amounts.

Quantitative $\beta$-glucuronidase activity was measured from MMY cultures of $R$. etli strains harboring transcriptional fusions as described previously (Granados-Baeza et al. 2007). After $10 \mathrm{~h}$ of growth, gene expression was induced using either $10 \mathrm{mM} \mathrm{NaNO}_{3}, 1.0 \mathrm{mM} \mathrm{NaNO}{ }_{2}$, or $100 \mu \mathrm{M} \mathrm{SNP}$. Quantitative $\beta$-glucuronidase activity was performed $2 \mathrm{~h}$ after induction on 1.0-ml culture samples, using as substrate 1.25 mM PNPG (4nitrophenyl $\beta$-D-glucuronide) (Girard et al. 2000). Protein concentration was determined using the Bradford reagent or by Lowry assay over a second set of $1.0-\mathrm{ml}$ samples. Specific activities are reported as nanomoles of product per minute per milligram of protein.

\section{PCR amplification.}

Specific PCR primers were designed using the Oligo 6.0 software and were purchased from Unidad de Síntesis Química IBt-UNAM (Cuernavaca, Mexico). PCR amplifications were done in a Mastercycler 5330 (Eppendorf, Hamburg, Germany). Accuprime high fidelity Taq DNA polymerase (Invitrogen) was used in PCR reactions with a cycling regime that includes a denaturing step at $94^{\circ} \mathrm{C}$ for $1 \mathrm{~min}$, followed by 30 cycles of $94^{\circ} \mathrm{C}$ for $30 \mathrm{~s}, 45$ to $60^{\circ} \mathrm{C}$ (according the primers' melting temperatures) for $30 \mathrm{~s}$, and $72^{\circ} \mathrm{C}$ for $90 \mathrm{~s}$. A final elongation step was made at $72^{\circ} \mathrm{C}$ for 5 to $10 \mathrm{~min}$, according to the length of the DNA fragment to be amplified.

\section{RT-PCR analysis.}

Total RNA was purified from both wild type and nirK mutant strains (nirK:: $\Omega \mathrm{Km}$, strain CFNX699 or nirK::loxP, strain CFNX702) grown under microaerobic conditions using the High Pure RNA isolation kit (Roche, Branchburg, NJ, U.S.A.). Single-stranded cDNA synthesis was performed using the RevertAid $\mathrm{H}$ Minus first-strand cDNA synthesis kit (Fermentas). Specific primers for genes forming the nirK operon analysis were designed and used to obtain RT-PCR products. The PCR products were analyzed by electrophoresis in agarose gels.

\section{5' RACE.}

Transcriptional start sites for the nirK and norC operons were identified in assays using the $5^{\prime}$ RACE system, version 2.0 (Invitrogen). scDNA was synthesized from $2 \mu \mathrm{g}$ of total RNA purified from microaerobic cultures of the wild-type strain derivatives carrying nirK and norC transcriptional fusions in plasmid pBBMCS53 (pNIC-01 and pNIC-03, respectively), using complementary primer gusLw (5'-ACAGGACGTAACA

Table 7. Bacterial strains and plasmids

\begin{tabular}{|c|c|c|}
\hline Strain or plasmid & Relevant characteristics $^{\mathbf{a}}$ & Reference \\
\hline \multicolumn{3}{|l|}{ Rhizobium etli } \\
\hline CFN42 & Wild type (type strain) & Quinto et al. 1982 \\
\hline CE3 & $\mathrm{Sm}^{\mathrm{r}}$ derivative of CFN42 & Noel et al. 1984 \\
\hline CFNX247 & CE3 derivative, nifA $\Delta:: \Omega \mathrm{Sp}-\mathrm{Sm}$ & Girard et al. 1996 \\
\hline CFNX637 & CE3 derivative, fix $K \mathrm{f}:: \Omega \mathrm{Km}$ & Girard et al. 2000 \\
\hline CFNX699 & CE3 derivative, nirK:: $\Omega \mathrm{Km}$ & Bueno et al. 2005 \\
\hline CFNX700 & CE3 derivative, $n n r R:: \operatorname{lox} \mathrm{P}$ & This work \\
\hline CFNX701 & CE3 derivative, norC::loxPSp & This work \\
\hline CFNX702 & CE3 derivative, nirk::lox $\mathrm{P}$ & This work \\
\hline \multicolumn{3}{|l|}{ Escherichia coli } \\
\hline DH5 $\alpha$ & 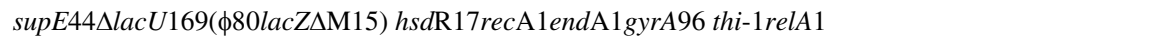 & Sambrook et al. 1989 \\
\hline HB101 & supE44 hsdS20 $\left(r_{-} m_{-B}\right)$ recA13 ara-14 proA2 lacY1 galK2 rpsL20 xyl-5 mtl-1 & Sambrook et al. 1989 \\
\hline BW21038 & DE3 lacX74 uidA ( $\Delta M l u 1)::$ pir $^{+}$miniTn5 $\mathrm{Lac}\left(\mathrm{Cm}^{\mathrm{r}}\right.$ lacI ${ }^{\mathrm{q}}$ lacZ $\left.\Delta \mathrm{M} 15\right)$ recA1 & Metcalf et al. 1996 \\
\hline \multicolumn{3}{|c|}{ 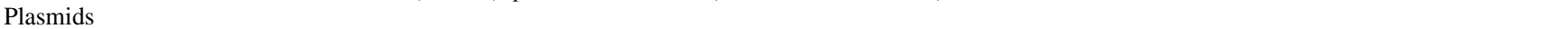 } \\
\hline $\mathrm{pSK}^{+}$ & Cloning vector, $\mathrm{Ap}^{\mathrm{r}}$ & Stratagene \\
\hline pCR2.1 TOPO & Cloning vector for polymerase chain reaction products, $\mathrm{Ap}^{\mathrm{r}} \mathrm{Km}^{\mathrm{r}}$ & Invitrogen \\
\hline pJQ200mp18 & Suicide cloning vector, $\mathrm{Gm}^{\mathrm{r}}$ & Quandt and Hynes 1993 \\
\hline $\mathrm{pK}^{*}$ mobsacB & Suicide cloning vector, $\mathrm{Km}^{\mathrm{r}}$ & Schäfer et al. 1994 \\
\hline pBBR1MCS5 & Broad-host-range cloning vector, $\mathrm{Gm}^{\mathrm{r}}$ & Kovach et al. 1995 \\
\hline pBBMCS53 & $\Delta$ placZ pBBR1MCS-5 derivative, carrying the promoterless uidA gene, $\mathrm{Gm}^{\mathrm{r}}$ & Girard et al. 2000 \\
\hline pRK2073 & Conjugation helper plasmid, $\mathrm{Sm} / \mathrm{Sp}^{\mathrm{r}}$ & Better and Helinski 1983 \\
\hline pRK2013 & Conjugation helper plasmid, $\mathrm{Km}^{\mathrm{r}}$ & Figurski and Helinski 1979 \\
\hline pRK415 & Broad-host-range plasmid, $\mathrm{Tc}^{\mathrm{r}}$ & Keen et al. 1988 \\
\hline pTR102 & Broad-host-range plasmid, $\mathrm{Tc}^{\mathrm{r}}$ & Weinstein et al. 1992 \\
\hline pNIC-01 & pBBMCS53 derivative norC::uid A & This work \\
\hline pNIC-02 & pBBMCS53 derivative $n n r S:: u i d \mathrm{~A}$ & This work \\
\hline pNIC-03 & $\begin{array}{l}\text { pBBMCS53 derivative nirK::uidA transcriptional fusion with 463-bp upstream NirK ATG, containing } \\
\text { anaeroboxes } 1,2 \text {, and } 3\end{array}$ & This work \\
\hline pNIC-04 & $\begin{array}{l}\text { pBBMCS53 derivative nirK::uidA transcriptional fusion with 133-bp upstream NirK ATG, containing } \\
\text { anaeroboxes } 1 \text { and } 2\end{array}$ & This work \\
\hline pNIC-05 & $\begin{array}{l}\text { pBBMCS53 derivative nirK::uidA transcriptional fusion with 103-bp upstream NirK ATG, containing } \\
\text { anaerobox } 1\end{array}$ & This work \\
\hline pNIC-06 & pBBMCS53 derivative nirK::uidA transcriptional fusion with specific mutations in anaerobox 1 & This work \\
\hline pNIC-07 & pBBMCS53 derivative nirK::uidA transcriptional fusion with specific mutations in anaerobox 2 & This work \\
\hline pGHN-01 & pNIC-03 derivative with the complete nirK coding region & This work \\
\hline pGHN-02 & pNIC-06 derivative with the complete nirK coding region & This work \\
\hline pGHN-03 & pNIC-07 derivative with the complete nirK coding region & This work \\
\hline pGHN-04 & pTR102 derivative carrying the nirK $K$ gene under the lac $Z$ promoter & This work \\
\hline pGHN-05 & pTR102 derivative carrying the $n n r R$ gene under the lacZ promoter & This work \\
\hline pGHN-06 & pRK 415 derivative carrying the fix $\mathrm{Kf}$ gene under the lac $Z$ promoter & This work \\
\hline pGHN-07 & $\mathrm{pK}^{*}$ mobsacB derivative, $n n r R::$ lox $\mathrm{PSp}$ & This work \\
\hline pGHN-08 & $\mathrm{pK}^{*}$ mobsacB derivative, nor $C:$ :loxPSp & This work \\
\hline pGHN-09 & pJQ200mp18 derivative, nirK::loxPSp & This work \\
\hline
\end{tabular}

${ }^{\mathrm{a}} \mathrm{Sm}, \mathrm{Sp}, \mathrm{Km}, \mathrm{Cm}, \mathrm{Ap}, \mathrm{Gm}$, and Tc = streptomycin, spectinomycin, kanamycin, chloramphenicol, gentamicin, and tetracyline, respectively. ${ }^{\mathrm{r}}=$ antibiotic resistance. 
TAAGGGACT-3') or norCGSP1 (5'-CGAGGAAGTCCGCGA GAT- $\left.3^{\prime}\right)$. After first-strand cDNA synthesis, the mRNA was removed by treatment with RNase and the scDNA was purified using a S.N.A.P. column. Terminal deoxynucleotidyl transferase and deoxycytidine triphosphate were used to add homopolymeric tails to the $3^{\prime}$ ends of the cDNA. Nested PCR reactions were done using gene-specific primers nirKGSP-2 (5'-AAGG ATCCACCTTCGGCCTTCTGCTGATG-3') (in positions 205 to 227) or norCGSP2 (5'-AAGCTCGAGACGTGTTTCCC-3') (in positions 171 to 184 ) and the abridged anchor primer (AAP, GGCCACGCGTCGACTAGTACGGGIIGGGIIGGGIIG, provided in the kit). The products were cloned into the pCR2.1 TOPO vector for sequencing.

\section{Plasmid construction.}

Specific mutagenesis of the $n n r R$ gene was done by PCR amplification of the corresponding genomic region from strain CE3, using the specific primers UpDRnnrR-BamHI (5'-CGGG ATCCGACCCGCGCACCATTCTCATT-3', underlined, introduced BamHI site) and LwDRnnrR-BamHI (5'-CGGGATCCG CAAACAGCAGCCACAGAACC- $3^{\prime}$, underlined, introduced BamHI site). The 2,345-bp PCR product (containing the $3^{\prime}$ end of $n i r V$, the complete coding region for $n n r R$, and the $5^{\prime}$ end of the $n n r U$ gene) was cloned by T-A annealing into pCR 2.1TOPO (Invitrogen). In this plasmid, a nnrR::loxPSp deletionsubstitution allele was generated by deleting a 49-bp sector (from nucleotide 233 to 282) by digestion with SmaI and inserting in its place a SmaI-SmaI loxPSp cartridge. The fragment containing the nnrR::loxPSp deletion-substitution allele was then removed by $B a m \mathrm{HI}$ digestion and was subcloned into BamHI-restricted pK*mobsacB vector (Schäfer et al. 1994), giving rise to plasmid $\mathrm{pGHN}-07$.

To introduce a mutation into the norC gene, a 1,475-bp product was obtained by PCR using total DNA from strain CE3 as template with the specific primers UpDRnorC-EcoRI (5'-CG AATTCCATCTCATGACGACCCTCTGG-3', EcoRI site underlined) and LwDRnorB-EcoRI (5'-CGGAATTCCAGGTTGAC GGGGTTGTAGAA-3', EcoRI site underlined). The EcoRI sites introduced by the primers were used to clone the fragment into the pSK+ vector (Stratagene, La Jolla, CA, U.S.A.). To construct a suicide plasmid useful for homogenotization, the EcoRI$X h o I$ fragment containing the norC allele was cloned into the EcoRI-SalI sites in pK*mobsacB (Schäfer et al 1994). Mutagenesis of the norC gene was achieved by introducing into the BamHI site (nucleotide 285) a loxPSp interposon (MartínezSalazar and Romero 2000), resulting in plasmid pGHN-08.

To introduce a mutation into the nirK gene, a 1,692-bp product was obtained by PCR using total DNA from strain CE3 as a template with primers UpnnrS-BamHI (5'-TTGGATCCTCG GAACTGCGGTGAGAAGGA-3', BamHI site underlined) and LwDRnirK-BamHI (5'-ATGGATCCAGCAGCCCACCTTTA GCGTAG-3', BamHI site underlined). The BamHI sites introduced by the primers were used to clone the fragment into the $\mathrm{pSK}^{+}-1$ vector (L. Girard, unpublished). Mutagenesis of the nirK gene was achieved by introducing into the EcoRI site (nucleotide 242 in the nirK coding region) a loxPSp interposon (Martínez-Salazar and Romero 2000). To construct a suicide plasmid (pGHN-09) useful for homogenotization, the BamHI fragment containing the nirK::loxPSp allele, was cloned into the BamHI site in pJQ200mp18 (Quandt and Hynes 1993).

To generate plasmids for expression analysis of the desired genes, the corresponding regulatory regions were cloned in the broad-host plasmid pBBRMCS53 (Girard et al. 2000) carrying a promoterless uidA gene. Plasmid pNIC-01, carrying a nor $:$ : uidA transcriptional fusion was constructed by cloning the EcoRI-XhoI 388-bp fragment synthesized by PCR with the specific primers NCUp-EcoRI (5'-TTAGAATTCCTCGGCCT
GCGT-3', EcoRI site underlined) and NCLw-XhoI (5'-AAG TCGAGACGTGTTTCCC-3', XhoI site underlined). The intergenic region $n n r S$-nirK was obtained by PCR using total DNA from strain CE3 and specific primers (UpnnrS-BamHI, 5'-TT GGATCCTCGGAACTGCGGTGAGAAGGA-3' and LwnirKBamHI 5'-AAGGATCCACCTTCGGCCTTCTGCTGATG-3', BamHI sites underlined). The BamHI 696-bp fragment was cloned in both directions in pBBMCS53 to obtain plasmids pNIC-02 and pNIC-03.

To construct transcriptional fusions containing deletions of the nirK upstream sequence, two PCR products were synthesized using primers UpnirK-gusM (5'-CAGGATCCAAGATG AGCCTTTGAACTTTG-3', BamHI site is underlined) or UpnirK-gusS (5'-AAGGATCCAAACAGCCAGTTTGCGCC AC-3', BamHI site is underlined) with primer LwnirK-BamHI. Fragments of 360 bp (containing the 133-bp upstream NirK start codon) and 329 bp (containing the 103-bp upstream NirK start codon) were cloned separately in pBBMCS53, giving plasmids pNIC-04 (nirK::uidA-M) and plasmid pNIC-05 (nirK:: uidA-S). The correct orientation of the fragments in the plasmids was verified by PCR using primer gusLw and the corresponding upper primer in each case.

Mutations of the putative FNR-binding sites (ANB1 and ANB2) in the nirK promoter region were introduced using the QuikChange site-directed mutagenesis kit (Stratagene). ANB1 was modified from TTGCG-N4-GTCAA to AT $\underline{\text { AACG-N4- }}$ GTCAA (nucleotides changed are underlined). The sequence of ANB2 was modified from TTGTG-N4-드르스 to TTGTGN4-GATAT (nucleotides underlined indicate the modifications). Both modified nirK regulatory regions were cloned in plasmid pBBMCS53 to obtain plasmids pNIC-06 and pNIC-07.

Four additional plasmids were constructed by cloning the complete nirK coding region downstream of the nirK regulatory regions present in plasmids pNIC-03, pNIC-06, and pNIC-07, to obtain plasmids pnirK-RRWT (pGHN-01), pnirK-ANB2m (pGHN-03), and pnirK-ANB1m (pGHN-02). Plasmids with nirK (pGHN-04), nnrR (pGHN-05), and fixKf (pGHN-06) genes constitutively expressed from the lac $Z$ promotor were obtained by cloning the respective coding region in the conjugative plasmids pTR102 or pRK415.

\section{R. etli mutant derivatives.}

Introduction of all mutant alleles into $R$. etli was carried out by homogenotization using the $s a c B$ marker present in pJQ200mp18 and pK*mobsacB vectors; this marker allows an easy selection for homogenotization events by scoring for resistance to sucrose. A $R$. etli strain containing nnrR::loxPSp, norC::loxPSp (CFNX701), and nirK::loxPSp alleles were constructed using plasmids pGHN-07, pGHN-08, and pGHN-09, respectively. Double recombinants were selected as $\mathrm{Sm}^{\mathrm{r}} \mathrm{Sp}^{\mathrm{r}} \mathrm{Km}^{\mathrm{s}}$

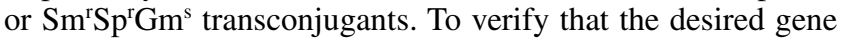
replacements had occurred, both plasmid profiles as well as total DNA blots of all the derivatives were analyzed by Southern hybridization against the appropriate gene and cassette probes. Strains CFNX700 (nnrR::loxP) and CFNX702 (nirK::loxP) were obtained using the cre-loxP system on double recombinant strains carrying $n n r R:$ loxPSp and nirK::loxPSp alleles (Martinez-Salazar and Romero 2000).

\section{Evaluation of nitrogen-fixation capacity.}

Three-day-old Phaseolus vulgaris cv. Negro Jamapa seedlings were inoculated with the desired strain and were grown in a greenhouse as previously described (Peralta et al. 2004). At 14 and $25 \mathrm{dpi}$, nine plants were analyzed for nitrogenase activity (by acetylene reduction) and nodule number as well as nodule and plant dry weight. Bacteria were isolated from nodules and their identities were verified by their antibiotic-resis- 
tance patterns. When necessary, after $14 \mathrm{dpi}$, plants were watered with $4 \mathrm{mM} \mathrm{KNO}_{3}$ for 12 days before harvesting.

\section{Quantification of Lb-NO complexes in bean nodules.}

For quantification of the percentage of $\mathrm{Lb}$ bound to $\mathrm{NO}$ within nodules, Lb extracts were prepared as reported previously (Meakin et al. 2007). Fresh nodules $(0.3 \mathrm{~g})$ were crushed in $4 \mathrm{ml}$ of $\mathrm{Lb}$ extraction buffer $\left(40 \mathrm{mM} \mathrm{Na} \mathrm{HPO}_{4} \cdot 2 \mathrm{H}_{2} \mathrm{O}, \mathrm{pH}\right.$ 7.4), $10 \mathrm{mM} \mathrm{NaH}_{2} \mathrm{PO}_{4} \cdot \mathrm{H}_{2} \mathrm{O}, \mathrm{pH} 7.4,0.02 \% \mathrm{~K}_{3} \mathrm{Fe}(\mathrm{CN})_{6}, 0.1 \%$ $\mathrm{NaHCO}_{3}$ ) and were centrifuged at $12,000 \times g$ at $4^{\circ} \mathrm{C}$ for 20 min. The supernatant was collected and used for assays. Absorption spectra from 300 to $700 \mathrm{~nm}$ at $25^{\circ} \mathrm{C}$ were obtained from $1 \mathrm{ml}$ of reduced and nitrosylated nodule extracts, using a Beckman DU 650 spectrophotometer. Absorption measurements were taken from the spectra to allow quantification of the nodular Lb-NO, following the protocol previously described by Meakin and associates (2007).

\section{Measurement of NO production and consumption.}

NO production and consumption in free-living cells was measured amperometrically using a NO electrode (Apollo 4000; World Precision Instruments, Inc., Sarasota, FL, U.S.A.) in a water-jacketed and magnetically stirred $\left(30^{\circ} \mathrm{C}\right)$ chamber. The membrane-covered electrode was situated at the bottom of the chamber, above the stirrer. For experimental assays, the chamber was filled to $2 \mathrm{ml}$ with $25 \mathrm{mM}$ phosphate buffer (pH7.4) and the cell suspension ( 0.2 to $0.3 \mathrm{mg}$ of protein for NO production and 4 to $5 \mathrm{mg}$ of protein for NO consumption). Oxygen present in the chamber was removed by incubating the cells for $5 \mathrm{~min}$ with glucose oxidase (to $4 \mathrm{U} / \mathrm{ml}$ ), catalase (to $20 \mathrm{U} / \mathrm{ml}$ ), sodium succinate (to $35 \mathrm{mM}$ ), and glucose (to 16 $\mathrm{mM})$. To determine NO production by the cells, $30 \mu \mathrm{l}$ of 50 $\mathrm{mM} \mathrm{NaNO}{ }_{2}$ were added with a Hamilton syringe, and NO production was analyzed by adding $100 \mu \mathrm{l}$ of a saturated NO solution $(1.91 \mathrm{mM})$.

\section{ACKNOWLEDGMENTS}

We are indebted to J. Mora and E. Bedmar for their support and stimulating discussions and to D. Romero and M. Dunn for critical review of the manuscript. We also thank J. Martínez-Salazar and M. Á. RamírezRomero for useful scientific advice, A. Leija for skillful technical assistance, O. Castillo and I. Rodríguez for help with greenhouse experiments, and P. Gaytán and E. López for oligonucleotide synthesis. Partial financial support for this research was provided by Programa de Apoyo a Proyectos de Investigación e Innovación Tecnológica, Universidad Nacional Autónoma de México (UNAM) (grants IN201406 and IN202109) and by UNAM-Consejo Superior de Investigaciones Científicas (CSIC) and Consejo Nacional de Ciencia y Tecnología (CONACYT)-CSIC (89537) cooperation agreements. N. Gómez-Hernández was supported during the Ph.D. program (Programa de Doctorado en Ciencias Biomédicas, Universidad Nacional Autónoma de México) by a scholarship from CONACYT (México).

\section{LITERATURE CITED}

Baek, S. H., and Shapleigh, J. P. 2005. Expression of nitrite and nitric oxide reductases in free-living and plant-associated Agrobacterium tumefaciens C58 cells. Appl. Environ. Microbiol. 71:4427-4436.

Baek, S. H., Hartsock, A., Shapleigh, J. P. 2008. Agrobacterium tumefaciens C58 uses ActR and FnrN to control nirK and nor expression. J. Bacteriol. 190:78-86.

Baudouin, E., Pieuchot, L., Engler, G., Pauly, N., Puppo, A. 2006. Nitric oxide is formed in Medicago truncatula-Sinorhizobium meliloti functional nodules. Mol. Plant. Microbe. Interact. 19:970-975.

Becker, A., Bergès, H., Krol, E., Bruand, C., Rüberg, S., Capela, D., Lauber, E., Meilhoc, E., Ampe, F., de Bruijn, F. J., Fourment, J., FrancezCharlot, A., Kahn, D., Küster, H., Liebe, C., Pühler, A., Weidner, S., Batut, J. 2004. Global changes in gene expression in Sinorhizobium meliloti 1021 under microoxic and symbiotic conditions. Mol. Plant. Microbe. Interact. 17:292-303.
Bedmar, E. J., Robles, E. F., and Delgado, M. J. 2005. The complete denitrification pathway of the symbiotic, nitrogen-fixing bacterium Bradyrhizobium japonicum. Biochem. Soc. Trans. 33:141-144.

Besson-Bard, A., Pugin, A., and Wendehenne, D. 2008. New insights intonitric oxide signaling in plants. Annu. Rev. Plant Biol. 59:21-39.

Better, M., and Helinski, D. P. 1983. Isolation and characterization of a recA gene of Rhizobium meliloti. J. Bacteriol. 115:311-316.

Bravo, A., and Mora, J. 1988. Ammonium assimilation in Rhizobium phaseoli by the glutamine synthetase-glutamate synthase pathway. J. Bacteriol. 170:980-984.

Brown, G. C., and Cooper, C. E. 1994. Nanomolar concentrations of nitric oxide reversibly inhibit synaptosomal respiration by competing with oxygen at cytochrome oxidase. FEBS (Fed. Eur. Biochem. Soc.) Lett. 356:295-298

Bueno, E., Gómez-Hernández, N., Girard, L., Bedmar, E. J., and Delgado, M. J. 2005. Function of the Rhizobium etli CFN42 nirK gene in nitrite metabolism. Biochem. Soc. Trans. 35:166-167.

Bueno, E., Mesa, S., Sanchez, C., Bedmar, E. J., Delgado, M. J. 2010. NifA is required for maximal expression of denitrification genes in $\mathrm{Bra}$ dyrhizobium japonicum. Environ. Microbiol. 12:393-400.

Cueto, M., Hernández-Perera, O., Martín, R., Bentura, M. L., Rodrigo, J. Lamas, S., Golvano, M. P. 1996. Presence of nitric oxide synthase activity in roots and nodules of Lupinus albus. FEBS (Fed. Eur. Biochem. Soc.) Lett. 398:159-164.

de Vries, S., Pouvreau, S., and Pouvreau L. A. M. 2007. Nitric oxide reductase: Structural variations and catalytic mechanism. Pages 57-66 in: Biology of the Nitrogen Cycle. H.Bothe, S. J. Ferguson, and W. E. Newton, eds. Elsevier, Amsterdam.

Delgado, M. J., Bonnard, N., Tresierra-Ayala, A., Bedmar, E. J., and Müller, P. 2003. The Bradyrhizobium japonicum napEDABC genes encoding the periplasmic nitrate reductase are essential for nitrate respiration. Microbiology 149:3395-3403.

Ferrarini, A., De Stefano, M., Baudouin, E., Pucciariello, C., Polverari, A.,Puppo, A., and Delledonne, M. 2008. Expression of Medicago truncatul genes responsive to nitric oxide in pathogenic and symbiotic conditions. Mol. Plant-Microbe Interact. 21:781-790.

Figurski, D. H., and Helinski, D. R. 1979. Replication of an origin-containing derivative of plasmid RK2 dependent on a plasmid function provided in trans. Proc. Natl. Acad. Sci. U.S.A. 76:1648-1652.

Girard, L., Valderrama, B., Palacios, R., Romero, D., and Dávila, G. 1996 Transcriptional activity of the symbiotic plasmid of Rhizobiurn etli is affected by different environmental conditions. Microbiology 142:28472856.

Girard, L., Brom, S., Dávalos, A., López, O., Soberón, M., and Romero, D. 2000. Differential regulation of fixN-reiterated genes in Rhizobium etli by a novel fixL-fixK cascade. Mol. Plant-Microbe Interact. 13:1283-1292.

González, V., Santamaría, R. I., Bustos, P., Hernández-González, I., Medrano-Soto, A., Moreno-Hagelsieb, G., Chandra Janga, S., Ramírez, M. A., Jiménez-Jacinto, V., Collado-Vides, J., and Dávila, G. 2006. The partitioned Rhizobium etli genome: Genetic and metabolic redundancy in seven interacting replicons. Proc. Natl. Acad. Sci. U.S.A. 103:3834-3839

Granados-Baeza, M. J., Gómez-Hernández, N., Mora, Y., Delgado, M. J., Romero, D., and Girard, L. 2007. Novel reiterated Fnr-type proteins control the production of the symbiotic terminal oxidase cbb3 in Rhizobium etli CFN42. Mol. Plant-Microbe Interact. 20:1241-1249.

Green, J., Scott, C., and Guest, J. R. 2001. Functional Versatility in the CRP-FNR Superfamily of Transcription Factors: FNR and FLP. Adv. Microb. Physiol. 44:1-34.

Hartsock, A., and Shapleigh, J. P. 2010. Identification, functional studies, and genomic comparisons of new members of the NnrR regulon in Rhodobacter sphaeroides. J. Bacteriol. 192:903-911.

Hendriks, J., Oubrie, A., Castresana, J., Urbani, A., Gemeinhardt, S., and Saraste, M. 2000. Nitric oxide reductases in bacteria. Biochim. Biophys. Acta. 1459:266-273.

Holloway, P., McCormick, W., Watson, R.J. and Chan, Y. K. 1996. Identification and analysis of the dissimilatory nitrous oxide reduction genes, nosRZDFY, of Rhizobium meliloti. J. Bacteriol. 178:1505-1514.

Hynes, M. F., and McGregor, N. F. 1990. Two plasmids other than the nodulation plasmid are necessary for formation of nitrogen-fixing nodules by Rhizobium leguminosarum. Mol. Microbiol. 4:567-574.

Kang, Y., Weber, K. D., Qiu, Y., Kiley, P. J., and Blattner, F. R. 2005. Genome-wide expression analysis indicates that FNR of Escherichia coli K-12 regulates a large number of genes of unknown function. J. Bacteriol. 187:1135-1160.

Kato, K., Kanahama, K., and Kanayama, Y. 2010. Involvement of nitric oxide in the inhibition of nitrogenase activity by nitrate in Lotus roo nodules. J. Plant. Physiol. 167:238-241.

Keen, N. T., Tamaki, S., Kobayashi, D., and Trollinger, D. 1988. Improved broad-host-range plasmids for DNA cloning in gram-negative bacteria. Gene 70:191-197. 
Kiley, P. J., and Beinert, H. 1999. Oxygen sensing by the global regulator, FNR: The role of the iron-sulfur cluster. FEMS (Fed. Eur. Microbiol. Soc.) Microbiol Rev. 22:341-352.

Kiley, P. J., and Beinert, H. 2003. The role of Fe-S proteins in sensing and regulation in bacteria. Curr. Opin. Microbiol. 6:181-185.

Körner, H., Sofia, H. J., and Zumft, W. G. 2003. Phylogeny of the bacterial superfamily of Crp-Fnr transcription regulators: Exploiting the metabolic spectrum by controlling alternative gene programs. FEMS (Fed. Eur. Microbiol. Soc.) Microbiol. Rev. 27:559-592.

Kovach, M. E., Elzer, P. H., Hill, D. S., Robertson, G. T., Farris, M. A., Roop II, R. M., and Peterson, K. M. 1995. Four new derivatives of the broad-host-range cloning vector pBBR1MCS, carrying different antibiotic-resistance cassettes. Gene 166:175-176.

Martínez-Salazar, J. M., and Romero, D. 2000. Role of the ruvB gene in homologous and homeologous recombination in Rhizobium etli. Gene 243:125-131.

Mathieu, C., Moreau, S., Frendo, P., Puppo, A., and Davies, M. J. 1998. Direct detection of radicals in intact soybean nodules: Presence of nitric oxide-leghemoglobin complexes. Free. Radic. Biol. Med. 24:12421249.

Mesa, S., Bedmar, E. J., Chanfon, A., Hennecke, H., and Fischer, H. M. 2003. Bradyrhizobium japonicum $\mathrm{NnrR}$, a denitrification regulator, expands the FixLJ-FixK2 regulatory cascade. J. Bacteriol. 185:39783982

Meakin, G. E., Bueno, E., Jepson, B., Bedmar, E. J., Richardson, D. J., and Delgado, M. J. 2007. The contribution of bacteroidal nitrate and nitrite reduction to the formation of nitrosylleghaemoglobin complexes in soybean root nodules. Microbiology 153:411-419.

Metcalf, W. W., Jiang, W., Daniels, L. L., Kim, S. K., Haldimann, A., and Wanner, B. L. 1996. Conditionally replicative and conjugative plasmids carrying lac $Z \alpha$ for cloning, mutagenesis, and allele replacement in bacteria. Plasmid 35:1-13.

Meyer, C., Lea, U. S., Provan, F., Kaiser, W. M., and Lillo, C. 2005. Is nitrate reductase a major player in the plant NO (nitric oxide) game? Photosyn. Res. 83:181-189.

Nagata, M., Murakami, E.-i., Shimoda, Y., Shimoda-Sasakura, F., Kucho,K.i., Suzuki, A., Abe, M., Higashi, S., and Uchiumi, T. 2008. Expression of a class 1 hemoglobin gene and production of nitric oxide in response to symbiotic and pathogenic bacteria in Lotus japonicus. Mol. PlantMicrobe Interact. 21:1175-1183.

Noel, K. D., Sánchez, A., Fernández, L., Leemans, J., and Cevallos, M. A. 1984. Rhizobium phaseoli symbiotic mutants with transposon Tn5 insertions. J. Bacteriol. 158:148-155.

Peralta, H., Mora, Y., Salazar, E., Encarnación, S., Palacios, R., and Mora, J. 2004. Engineering the nifH promoter region and abolishing poly- $\beta$ hydroxybutyrate accumulation in Rhizobium etli enhance nitrogen fixation in symbiosis with Phaseolus vulgaris. Appl. Environ. Microbiol. 70:3272-3281.

Philippot, L. 2002 Denitrifying genes in bacterial and archaeal genomes. Biochim. Biophys. Acta. 1577:355-376.

Pii, Y., Crimi, M., Cremonese, G., Spena, A., and Pandolfini, T. 2007. Auxin and nitric oxide control indeterminate nodule formation. BMC Plant Biol. 7:21.

Quinto, C., de la Vega, H., Flores, M., Fernández, L., Ballado, T., Soberón, G., and Palacios, R. 1982. Reiteration of nitrogen fixation gene sequences in Rhizobium phaseoli. Nature 299:724-726.

Quandt, J., and Hynes, M. F. 1993. Versatile suicide vectors which allow direct selection for gene replacement in gram-negative bacteria. Gene 127:15-21.

Robles, E. F., Sánchez, C., Bonnard, N., Delgado, M. J., and Bedmar, E. J. 2006. The Bradyrhizobium japonicum napEDABC genes are controlled by the FixLJ-FixK(2)-NnrR regulatory cascade. Biochem. Soc. Trans. 34(Pt 1):108-110.

Sambrook, J., Fritsch, E. F., and Maniatis, T. 1989. Molecular Cloning. A Laboratory Manual. 2nd ed. Cold Spring Harbor Laboratory Press. Cold Spring Harbor, NY, U.S.A.

Sánchez, C., Gates, A. J., Meakin, G. E., Uchiumi, T., Girard, L., Richardson, D. J., Bedmar, E. J., and Delgado, M. J. 2010. Production of nitric oxide and nitrosylleghemoglobin complexes in soybean nodules in response to flooding. Mol. Plant-Microbe Interact. 23:702-711.

Sasakura, F., Uchiumi, T., Shimoda, Y., Suzuki, A. Takenouchi, K., Higashi,
S., and Abe, M. 2006. A class 1 hemoglobin gene from Alnus firma functions in symbiotic and nonsymbiotic tissues to detoxify nitric oxide. Mol. Plant-Microbe Interact. 19:441-450.

Schäfer, A., Tauch, A., Jager, W., Kalinowski, J., Thierbach, G., and Puhler, A. 1994. Small mobilizable multi-purpose cloning vectors derived from the Escherichia coli plasmids pK18 and pK19: Selection of defined deletions in the chromosome of Corynebacterium glutamicum. Gene 145:69-73.

Shapleigh, J. P. 2006. The denitrifying prokaryotes. Pages 769-792 in: Prokaryotes. Vol. 2. M. Dworkin, S. Falkow, E. Rosenberg, K.-H. Schleifer, and E. Stackebrandt, eds. Springer, New York.

Shimoda, Y., Nagata, M., Suzuki, A., Abe, M., Sato, S., Kato, T., Tabata, S., Higashi, S., and Uchiumi, T. 2005. Symbiotic rhizobium and nitric oxide induce gene expression of non-symbiotic hemoglobin in Lotus japonicus. Plant. Cell. Physiol. 46:99-107.

Shimoda, Y., Shimoda-Sasakura, F., Kucho, K., Kanamori, N., Nagata, M., Suzuki, A., Abe, M., Higashi, S., and Uchiumi, T. 2009. Overexpression of class 1 plant hemoglobin genes enhances symbiotic nitrogen fixation activity between Mesorhizobium loti and Lotus japonicus. Plant J. 57:254-63.

Stöhr, C., Strube, F., Marx, G., Ullrich, W. R., and Rockel, P. 2001. A plasma membrane-bound enzyme of tobacco roots catalyses the formation of nitric oxide from nitrite. Planta 212:835-841.

Tate, R., Riccio, A., Iaccarino, M., and Patriarca, E. J. 1997. A cysG mutant strain of Rhizobium etli pleiotropically defective in sulfate and nitrate assimilation. J. Bacteriol. 179:7343-7350.

Toffanin, A., Wu, Q., Maskus, M., Caselia, S., Abruna, H. D., and Shapleigh, J. P. 1996. Characterization of the gene encoding nitrite reductase and the physiological consequences of its expression in the nondenitrifying Rhizobium "hedysari" strain HCNT1. Appl. Environ. Microbiol. 62:4019-4025.

Tosques, I. E., Kwiatkowski, A. V., Shi, J., and Shapleigh, J. P. 1997. Characterization and regulation of the gene encoding nitrite reductase in Rhodobacter sphaeroides 2.4.3. J. Bacteriol. 179:1090-1095.

Trinchant, J. C., and Rigaud, J. 1982. Nitrite and nitric oxide as inhibitors of nitrogenase from soybean bacteroids. Appl. Environ. Microbiol. 44:1385-1388.

van Spanning, R. J., Delgado, M. J., and Richardson, D. J. 2005. The nitrogen cycle: Denitrification and its relationship to $\mathrm{N}_{2}$ fixation. Pages 277-342 in: Nitrogen Fixation in Agriculture, Forestry, Ecology and the Environment. D. Werner and W. E. Newton, eds. Springer, Dortrecht, The Netherlands.

van Spanning, R. J., Richardson, D. J., and Ferguson, S. J. 2007. Introduction to the biochemistry and molecular biology of denitrification. Pages 3-20 in: Biology of the Nitrogen Cycle. H. Bothe, S. J. Ferguson, and W. E. Newton, eds. Elsevier, Amsterdam.

Wang, H., Tseng, C. P., and Gunsalus, R. P. 1999. The napF and narG nitrate reductase operons in Escherichia coli are differentially expressed in response to submicromolar concentrations of nitrate but not nitrite. J. Bacteriol. 181:5303-5308.

Weinstein, M., Roberts, R. C., and Helinski, D. R. 1992. A region of the broad-host-range plasmid RK2 causes stable in planta inheritance of plasmids in Rhizobium meliloti cells isolated from alfalfa root nodules. J. Bacteriol. 174:7486-7489.

Wing, H. J., Willliams, S. M., and Busby, S. J. 1995. Spacing requirements for transcription activation by Escherichia coli FNR protein. J. Bacteriol. 177:6704-6710.

Zumft, W. G. 2002. Nitric oxide signaling and NO dependent transcriptional control in bacterial denitrification by members of the FNR-CRP regulator family. J. Mol. Microbiol. Biotechnol. 4:277-286.

Zumft, W. G. 2005. Nitric oxide reductases of prokaryotes with emphasis on the respiratory, heme-copper oxidase type. J. Inorg. Biochem. 99:194-215.

Zumft, W. G., and Korner, H. 1997. Enzyme diversity and mosaic gene organization in denitrification. Antonie Van Leeuwenhoek 71:43-58

\section{AUTHOR-RECOMMENDED INTERNET RESOURCE}

Kazusa DNA Research Institute Rhizobase database: bacteria.kazusa.or.jp/rhizobase 